\title{
Corrosion inhibition effect and adsorption behaviour of nicotinamide derivatives on mild steel in hydrochloric acid solution
}

\author{
M. P. Chakravarthy $\cdot$ K. N. Mohana • \\ C. B. Pradeep Kumar
}

Received: 15 February 2014/ Accepted: 12 July 2014/Published online: 26 August 2014

(C) The Author(s) 2014. This article is published with open access at Springerlink.com

\begin{abstract}
Background A new class of nicotinamide derivatives viz., $N$-((1H-pyrrol-2-yl)methylene)nicotinamide, $N$-((methyl(phenyl)amino)methylene)nicotinamide, $N$-nicotinoylbenzimidothioic acid and $N$-(4-(methylthio)benzylidene)nicotinamide have been synthesized and their corrosion inhibition effect on mild steel in $0.5 \mathrm{M} \mathrm{HCl}$ was investigated by mass loss, Tafel polarization technique and $\mathrm{AC}$ impedance measurements.

Results The inhibition efficiency of the inhibitors on mild steel in $0.5 \mathrm{M} \mathrm{HCl}$ has been studied based on concentration, time interval and temperature. Potentiodynamic polarization studies showed that all the examined inhibitors suppress both anodic and cathodic process and behave as mixed type of corrosion inhibitors.

Conclusions The adsorption of all the inhibitors was found to obey Langmuir isotherm model. Electrochemical impedance data revealed that polarization resistance $\left(R_{\mathrm{P}}\right)$ increases and double layer capacitance $\left(C_{\mathrm{dl}}\right)$ decreases as the concentration of the inhibitors increases. FTIR, EDX and SEM analyses were performed to study the film persistency of the inhibitors.
\end{abstract}

Keywords Corrosion inhibition - Nicotinamide derivatives - Adsorption - Electrochemical techniques . Thermodynamic properties

M. P. Chakravarthy · K. N. Mohana $(\bowtie) \cdot$ C. B. Pradeep Kumar Department of Studies in Chemistry, University of Mysore, Manasagangothri, Mysore 570 006, India e-mail: drknmohana@gmail.com

\section{Background}

Mild steel (MS) is a class of strong and tough steel that contains a low quantity of carbon. MS has relatively low tensile strength, but it is cheap and malleable, and its surface hardness can be increased through carburizing. It is the most important engineering material particularly for structural, instrumental, industrial and automobile applications. But it is highly susceptible to corrosion especially in acidic media [1]. Corrosion problem occurs in many industries, and can cause disastrous damage to metal and alloy structures causing economic consequences in terms of repair, replacement and product losses. Hence, various corrosion protection technologies have been employed, among them; the use of inhibitors is one of the practical methods for preventing corrosion of MS especially in acid media [2]. A wide variety of corrosion inhibitors ranging from rare earth elements [3] to organic compounds [4-7] have been used. The corrosion inhibition property of inhibitors depends on their molecular structures, planarity and the lone pairs of electrons present on the hetero atoms, which determine the adsorption of these molecules on the metallic surfaces. Corrosion inhibitors block the active sites and enhance the adsorption process, thus decreasing the rate of dissolution and extending the life span of the equipment $[8,9]$.

Although, several organic compounds have been used as inhibitors in different corrosive environment, choosing an appropriate inhibitor for specific environment and metal is of great importance. Generally, oxygen, nitrogen and sulphur containing heterocyclic organic compounds with multiple bonds have a tendency to resist corrosion $[10,11]$. Compounds rich in heteroatoms can be regarded as environmental friendly inhibitors because of their characteristic strong chemical activity and low toxicity [12]. The 
adsorption characteristics of organic molecules are also affected by sizes, electron density at the donor atoms and orbital character of donating electrons [13-16]. Organic compounds containing hetero atoms in the functional groups, pi-electron in triple or conjugated double bonds and presence of aromatic rings in their structure are the major adsorption centres and are usually good inhibitors [17]. Several heterocyclic compounds such as methylthiophenyl derivatives [18], isoxazolium cationic Schiff base compounds [19], quinoline derivatives [20], sulphonamide compounds [21], thiadiazoles derivatives [22], imidazole derivatives [23], fluoroquinolones [24], pyrazole derivatives [25], pyridazine derivatives [26] and pyridine derivatives [27] have been reported as anticorrosion substances in various corrosive environments.

In the present investigation attempts have been made to study the inhibitive effect of the four newly synthesized nicotinamide derivatives such as $N-((1 \mathrm{H}-$ pyrrol-2-yl $)$ methylene)nicotinamide $\quad(\mathrm{PMN}), \quad N-(($ methyl(phenyl)amino)methylene)nicotinamide (MMN), $N$-nicotinoylbenzimidothioic acid (NBT) and $N$-(4-(methylthio)benzylidene)nicotinamide (MBN), on the corrosion of MS in $0.5 \mathrm{M}$ $\mathrm{HCl}$ using mass loss and electrochemical techniques. The experimental results were discussed with various activation and adsorption thermodynamic parameters. The passive film formed on the metal surface was characterized by FTIR, SEM and EDX. Further, the inhibition performances of the four derivatives have been compared and discussed.

\section{Experimental}

\section{Materials}

MS specimen used in the present study having the following chemical compositions (in wt\%): $\mathrm{C} 0.051 ; \mathrm{Mn}$ 0.179; Si 0.006; P 0.005; S 0.023; Cr 0.051; Ni 0.05; Mo 0.013; Ti 0.004; Al 0.103; Cu 0.050; Sn 0.004; B 0.00105; Co 0.017 ; $\mathrm{Nb} 0.012 ; \mathrm{Pb} 0.001$ and the remainder iron. For all experiments, square type MS specimens of dimension $2 \mathrm{~cm} \times 2 \mathrm{~cm} \times 0.1 \mathrm{~cm}$ were used. The specimens were mechanically well polished with different grades $\mathrm{SiC}$ (200-600) emery papers, degreased with benzene, washed with doubly distilled water and finally dried. All solvents and chemicals used were of AR grade, and used as such. Doubly distilled water was used in the preparation of the various concentrations of test solutions.

Synthesis of inhibitors

The nicotinamide derivatives, PMN, MMN, NBT and MBN have been synthesized by the literature method [28].

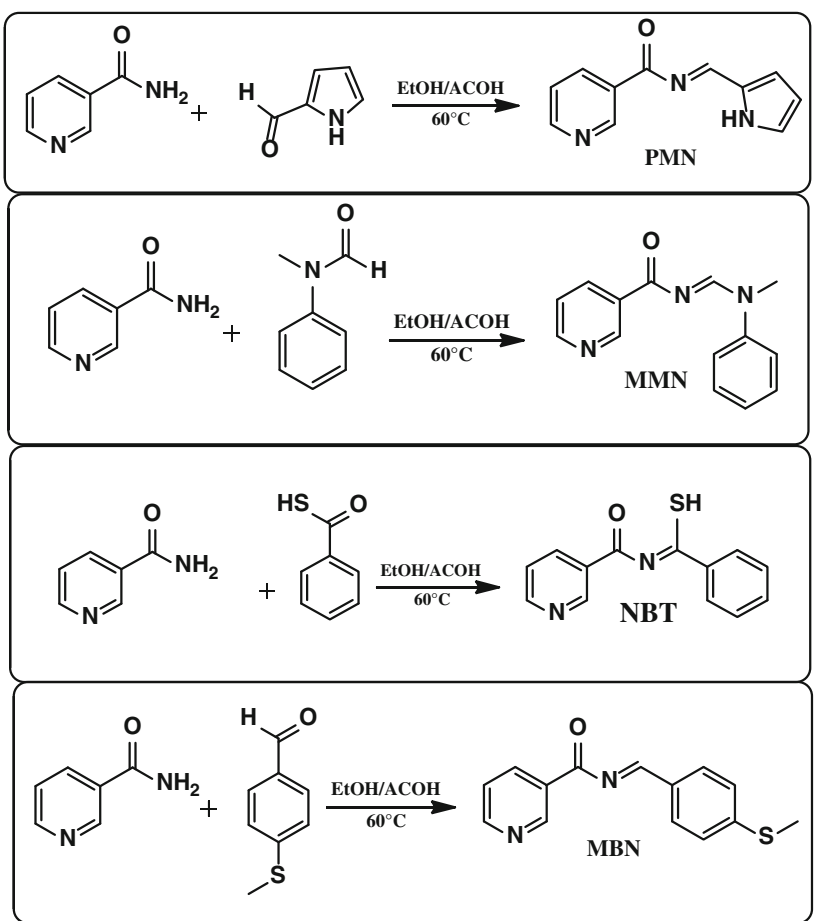

Fig. 1 Synthetic scheme of PMN, MMN, NBT and MBN

PMN was synthesized by dissolving $0.61 \mathrm{~g}(5 \mathrm{mmol})$ of nicotinamide $\left(\mathrm{C}_{6} \mathrm{H}_{6} \mathrm{~N}_{2} \mathrm{O}\right.$, Mol. Wt. 122.12) in $15 \mathrm{~mL}$ of ethanol in a round bottom flask. To this $0.47 \mathrm{~g}(5 \mathrm{mmol})$ of pyrrole-2-carboxaldehyde $\left(\mathrm{C}_{5} \mathrm{H}_{5} \mathrm{NO}\right.$, Mol. Wt. 95.10) in $15 \mathrm{~mL}$ ethanol was mixed and refluxed for $6 \mathrm{~h}$ at $60^{\circ} \mathrm{C}$ temperature in the presence of few drops glacial acetic acid, and then the solution was concentrated using rotor vaporizer and kept for dry in vacuum. MMN was synthesized by dissolving $0.61 \mathrm{~g}(5 \mathrm{mmol})$ of nicotinamide in $15 \mathrm{~mL}$ of ethanol in a round bottom flask. To this $0.62 \mathrm{~mL}$ ( $5 \mathrm{mmol})$ of $\mathrm{N}$-methylformanilide $\left(\mathrm{C}_{8} \mathrm{H}_{9} \mathrm{NO}\right.$, Mol. Wt. 135.16) in $15 \mathrm{~mL}$ ethanol was mixed and refluxed for $6 \mathrm{~h}$ at $60{ }^{\circ} \mathrm{C}$ temperature in the presence of few drops glacial acetic acid, and then the solution was concentrated using rotor vaporizer and kept for dry in vacuum.

NBT was synthesized by dissolving $0.61 \mathrm{~g}(5 \mathrm{mmol})$ of nicotinamide in $15 \mathrm{~mL}$ of ethanol in a round bottom flask. To this $0.58 \mathrm{~mL}(5 \mathrm{mmol})$ of thiobenzoic acid $\left(\mathrm{C}_{7} \mathrm{H}_{6} \mathrm{OS}\right.$, Mol. Wt. 138.19) dissolved in $15 \mathrm{~mL}$ of ethanol was added and refluxed for $6 \mathrm{~h}$ with stirring at $60{ }^{\circ} \mathrm{C}$ temperature in the presence of few drops of glacial acetic acid. Then the solution was concentrated using rotor vaporizer and kept for dry in vacuum and the product obtained was collected. MBN was synthesized by dissolving $0.61 \mathrm{~g}(5 \mathrm{mmol})$ of nicotinamide in $15 \mathrm{~mL}$ of ethanol in a round bottom flask. To this a $0.66 \mathrm{~mL}(5 \mathrm{mmol})$ of the 4-(methylthio)benzaldehyde $\left(\mathrm{C}_{8} \mathrm{H}_{8} \mathrm{OS}\right.$, Mol. Wt. 152.21) dissolved in $15 \mathrm{~mL}$ of ethanol was added and refluxed for $6 \mathrm{~h}$ with stirring at 


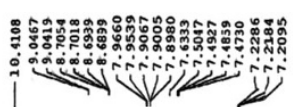

(a)

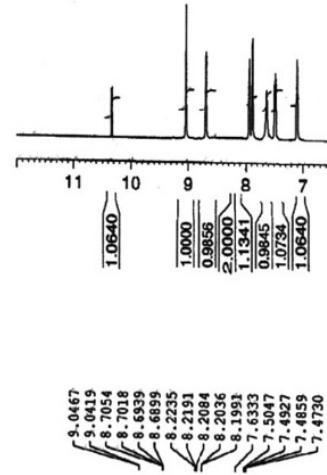

(c)
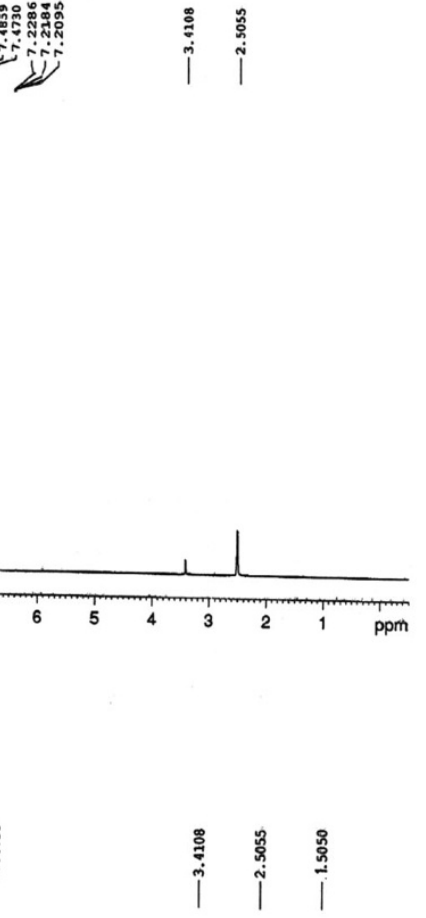

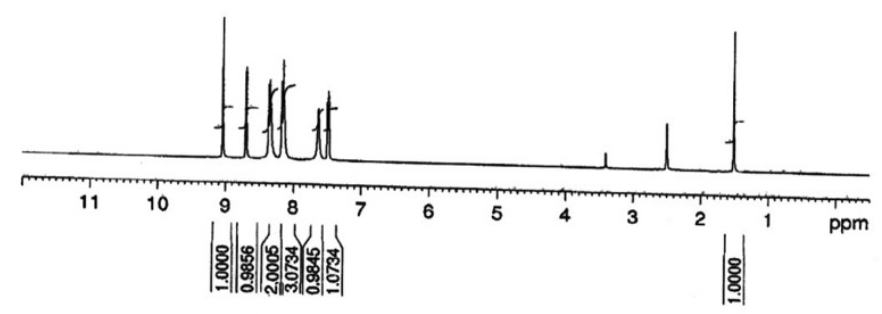

Fig. $2{ }^{1} \mathrm{H}-\mathrm{NMR}$ spectrum of a PMN, b MMN, c NBT and d MBN

$60{ }^{\circ} \mathrm{C}$ temperature in presence of glacial acetic acid. Then the solution was concentrated using rotor vaporizer and kept for dry in vacuum and the product obtained was collected. The synthetic schemes of PMN, MMN, NBT and MBN are shown in Fig. 1.

The Chemical structures of the compounds are characterized by FTIR, ${ }^{1} \mathrm{H}-\mathrm{NMR}$ and Mass spectral studies. PMN $\left(\mathrm{C}_{11} \mathrm{H}_{9} \mathrm{~N}_{3} \mathrm{O}\right.$, Mol. Wt. 199.21): Yield: $89 \%$, Melting Range (M. R, $\left.{ }^{\circ} \mathrm{C}\right): 98-102$. FTIR $\left(\mathrm{KBr}, \mathrm{cm}^{-1}\right): 1,457(\mathrm{NH})$, $1,645 \quad(\mathrm{~N}=\mathrm{C}), \quad 1,726 \quad(\mathrm{C}=\mathrm{O}) . \quad{ }^{1} \mathrm{H}-\mathrm{NMR} \quad(400.15 \mathrm{MHz}$, DMSO-d6) $\delta$ ppm: $7.22-7.20(\mathrm{t}, \quad J=4.0 \mathrm{~Hz}, 1 \mathrm{H})$, $7.50-7.47(\mathrm{q}, 1 \mathrm{H}), 7.63(\mathrm{~s}, 1 \mathrm{H}), 7.90-7.89(\mathrm{t}, J=4.2 \mathrm{~Hz}$,

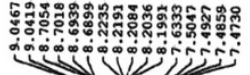

|

(b)
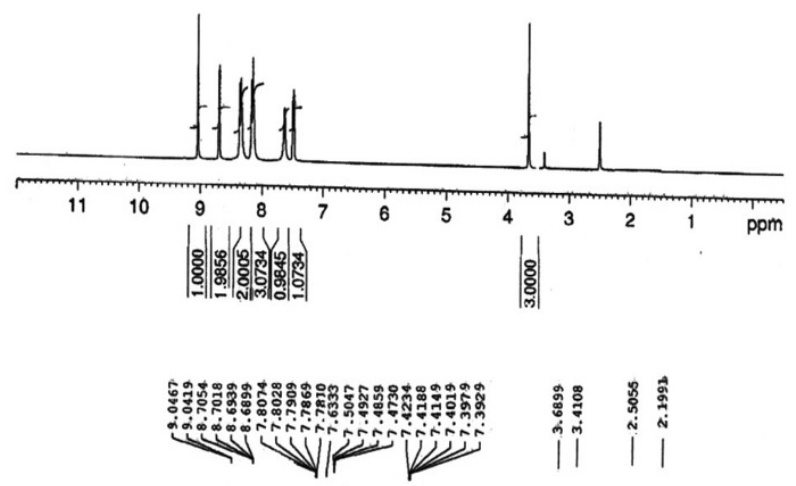

(d)

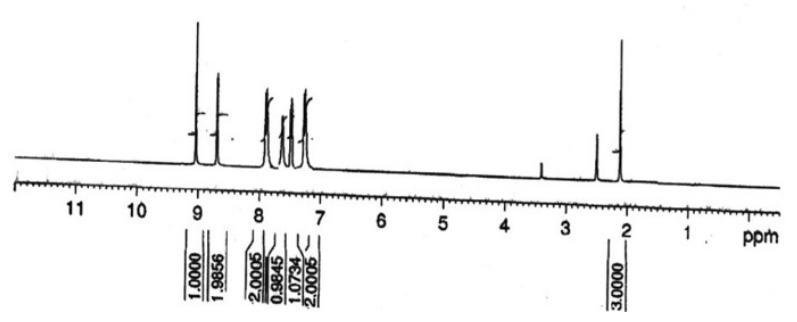

1H), 7.96-7.95 (d, $J=4.8 \mathrm{~Hz}, 2 \mathrm{H}), \quad 8.70-8.68 \quad(\mathrm{t}$, $J=3.8 \mathrm{~Hz}, 1 \mathrm{H}), 9.046-9.041(\mathrm{~d}, J=2.0 \mathrm{~Hz}, 1 \mathrm{H}), 10.41$ (s, 1H). MS, m/z: $200(\mathrm{M}+1)$. Elemental analyses found (calculated) for $\mathrm{C}_{11} \mathrm{H}_{9} \mathrm{~N}_{3} \mathrm{O}(\%)$ : C, 66.29 (66.32): $\mathrm{H}, 4.50$ (4.55): N, 20.96 (21.09), O, 7.98 (8.03). ${ }^{1} \mathrm{H}-\mathrm{NMR}$ spectrum of PMN is shown in Fig. 2a.

MMN $\left(\mathrm{C}_{14} \mathrm{H}_{13} \mathrm{~N}_{3} \mathrm{O}\right.$, Mol. Wt. 239.27): Yield: $79 \%$, Melting Range (M. R, $\left.{ }^{\circ} \mathrm{C}\right)$ : 106-108. FTIR $\left(\mathrm{KBr}, \mathrm{cm}^{-1}\right)$ : $1,630 \quad(\mathrm{~N}=\mathrm{C}), \quad 1,710 \quad(\mathrm{C}=\mathrm{O}) . \quad{ }^{1} \mathrm{H}-\mathrm{NMR} \quad(400.15 \mathrm{MHz}$, DMSO-d6) $\delta$ ppm: 3.68 (s, 3H), 7.50-7.47 (q, 1H), 7.63 $(\mathrm{s}, \quad 1 \mathrm{H}), \quad 8.20-8.19(\mathrm{~d}, \quad J=1.8 \mathrm{~Hz}, \quad 3 \mathrm{H}), \quad 8.22-8.20$ $(\mathrm{t}, \quad J=4.0 \mathrm{~Hz}, 2 \mathrm{H}), \quad 8.70-8.68 \quad(\mathrm{q}, 2 \mathrm{H}), \quad 9.046-9.041$ 
Table $1 C_{\mathrm{R}}$ and IE (\%) obtained from mass loss measurements of MS in $0.5 \mathrm{M} \mathrm{HCl}$ solution containing various concentrations of PMN, MMN, $\mathrm{NBT}$ and $\mathrm{MBN}$ at different temperatures

\begin{tabular}{|c|c|c|c|c|c|c|c|c|c|}
\hline \multirow[t]{2}{*}{$T\left({ }^{\circ} \mathrm{C}\right)$} & \multirow[t]{2}{*}{$C(\mathrm{ppm})$} & \multicolumn{2}{|l|}{ PMN } & \multicolumn{2}{|l|}{ MMN } & \multicolumn{2}{|l|}{ NBT } & \multicolumn{2}{|l|}{$\mathrm{MBN}$} \\
\hline & & $C_{\mathrm{R}}\left(\mathrm{mg} \mathrm{cm}^{-2} \mathrm{~h}^{-1}\right)$ & IE $(\%)$ & $C_{\mathrm{R}}\left(\mathrm{mg} \mathrm{cm}^{-2} \mathrm{~h}^{-1}\right)$ & IE $(\%)$ & $C_{\mathrm{R}}\left(\mathrm{mg} \mathrm{cm}^{-2} \mathrm{~h}^{-1}\right)$ & IE $(\%)$ & $C_{\mathrm{R}}\left(\mathrm{mg} \mathrm{cm}^{-2} \mathrm{~h}^{-1}\right)$ & $\mathrm{IE}(\%)$ \\
\hline \multirow[t]{5}{*}{30} & Blank & 0.7200 & - & 0.7200 & - & 0.7200 & - & 0.7200 & - \\
\hline & 200 & 0.2324 & 67.6 & 0.1979 & 72.6 & 0.1582 & 78.1 & 0.1340 & 81.4 \\
\hline & 300 & 0.1875 & 74.0 & 0.1520 & 78.9 & 0.1307 & 81.9 & 0.0987 & 86.3 \\
\hline & 400 & 0.1715 & 76.2 & 0.1288 & 82.1 & 0.1074 & 85.1 & 0.0718 & 90.0 \\
\hline & 500 & 0.1400 & 80.6 & 0.0984 & 86.3 & 0.0811 & 88.7 & 0.0464 & 93.6 \\
\hline \multirow[t]{5}{*}{40} & Blank & 0.9490 & - & 0.9490 & - & 0.9490 & - & 0.9490 & - \\
\hline & 200 & 0.3202 & 66.2 & 0.2711 & 71.4 & 0.2180 & 77.0 & 0.1878 & 80.2 \\
\hline & 300 & 0.2814 & 70.3 & 0.2315 & 75.6 & 0.1959 & 79.3 & 0.1514 & 84.0 \\
\hline & 400 & 0.2381 & 74.9 & 0.1879 & 80.2 & 0.1611 & 83.0 & 0.1109 & 88.3 \\
\hline & 500 & 0.2049 & 78.4 & 0.1500 & 84.2 & 0.1207 & 87.3 & 0.0786 & 91.7 \\
\hline \multirow[t]{5}{*}{50} & Blank & 1.1520 & - & 1.1520 & - & 1.1520 & - & 1.1520 & - \\
\hline & 200 & 0.4090 & 64.5 & 0.3557 & 69.1 & 0.2846 & 75.3 & 0.2491 & 78.4 \\
\hline & 300 & 0.3562 & 69.1 & 0.2994 & 74.0 & 0.2532 & 78.0 & 0.1928 & 83.3 \\
\hline & 400 & 0.3142 & 72.7 & 0.2473 & 78.5 & 0.2206 & 80.8 & 0.1670 & 85.5 \\
\hline & 500 & 0.2676 & 76.8 & 0.2036 & 82.3 & 0.1645 & 85.7 & 0.1112 & 90.3 \\
\hline \multirow[t]{5}{*}{60} & Blank & 1.4350 & - & 1.4350 & - & 1.4350 & - & 1.4350 & - \\
\hline & 200 & 0.5376 & 62.5 & 0.4687 & 67.3 & 0.3895 & 72.9 & 0.3551 & 75.3 \\
\hline & 300 & 0.4555 & 68.3 & 0.3864 & 73.1 & 0.3277 & 77.2 & 0.2552 & 82.2 \\
\hline & 400 & 0.4235 & 70.5 & 0.3502 & 75.6 & 0.2871 & 80.0 & 0.2248 & 84.3 \\
\hline & 500 & 0.3606 & 74.9 & 0.2730 & 81.0 & 0.2293 & 84.0 & 0.1764 & 87.7 \\
\hline
\end{tabular}

(d, $J=2.0 \mathrm{~Hz}, 1 \mathrm{H}) . \mathrm{MS}, \mathrm{m} / z: 240(\mathrm{M}+1)$. Elemental analyses found (calculated) for $\mathrm{C}_{14} \mathrm{H}_{13} \mathrm{~N}_{3} \mathrm{O}(\%)$ : C, 70.19 (70.28): H, 5.41 (5.48): N, 17.48 (17.56), O, 6.57 (6.69).

${ }^{1} \mathrm{H}-\mathrm{NMR}$ spectrum of MMN is shown in Fig. $2 \mathrm{~b}$.

NBT $\left(\mathrm{C}_{13} \mathrm{H}_{10} \mathrm{~N}_{2} \mathrm{OS}\right.$, Mol. Wt. 242.30): Yield: $83 \%$, Melting Range (M. R, $\left.{ }^{\circ} \mathrm{C}\right): 82-84$. FTIR $\left(\mathrm{KBr}, \mathrm{cm}^{-1}\right): 723$ $(\mathrm{C}-\mathrm{S}), 1,643(\mathrm{~N}=\mathrm{C}), 1,726(\mathrm{C}=\mathrm{O}) .{ }^{1} \mathrm{H}-\mathrm{NMR}(400.15 \mathrm{MHz}$, DMSO-d6) $\delta$ ppm: 1.50 (s, 1H), 7.50-7.47 (q, 1H), 7.63 (s, $1 \mathrm{H}), \quad 8.20-8.19(\mathrm{~d}, \quad J=1.8 \mathrm{~Hz}, 3 \mathrm{H}), \quad 8.22-8.20 \quad(\mathrm{t}$, $J=4.2 \mathrm{~Hz}, 2 \mathrm{H}), 8.70-8.68$ (q, 1H), 9.046-9.041 (d, $J=2.0 \mathrm{~Hz}, 1 \mathrm{H}) . \mathrm{MS}, m / z: 243(\mathrm{M}+1)$. Elemental analyses found (calculated) for $\mathrm{C}_{13} \mathrm{H}_{10} \mathrm{~N}_{2} \mathrm{OS}(\%)$ : C, 64.38 (64.44): H, 4.07 (4.16): N, 11.44 (11.56), O, 6.58 (6.60), S, 13.17 (13.23). ${ }^{1} \mathrm{H}-\mathrm{NMR}$ spectrum of NBT is shown in Fig. 2c.

MBN $\left(\mathrm{C}_{14} \mathrm{H}_{12} \mathrm{~N}_{2} \mathrm{OS}\right.$, Mol. Wt. 256.32): Yield: $85 \%$, Melting Range (M. R, $\left.{ }^{\circ} \mathrm{C}\right):$ 90-94. FTIR (KBr, cm $\left.{ }^{-1}\right): 667$ $(\mathrm{C}-\mathrm{S}), 1,587(\mathrm{~N}=\mathrm{C}), 1,697(\mathrm{C}=\mathrm{O}) .{ }^{1} \mathrm{H}-\mathrm{NMR}(400.15 \mathrm{MHz}$, DMSO-d6) $\delta$ ppm: 2.19 (s, 3H), 7.42-7.39 (m, 2H), $7.50-7.47$ (q, 1H), $7.63(\mathrm{~s}, 1 \mathrm{H}), 7.80-7.78(\mathrm{~m}, 2 \mathrm{H})$, 8.70-8.68 (q, 2H), 9.046-9.041 (d, $J=2.0 \mathrm{~Hz}, 1 \mathrm{H})$. MS, $\mathrm{m} / \mathrm{z}: 257(\mathrm{M}+1)$. Elemental analyses found (calculated) for $\mathrm{C}_{14} \mathrm{H}_{12} \mathrm{~N}_{2} \mathrm{OS}$ (\%): C, 65.54 (65.60): H, 4.68 (4.72): $\mathrm{N}$, 10.89 (10.93), O, 6.19 (6.24), S, 12.47 (12.51). ${ }^{1} \mathrm{H}-\mathrm{NMR}$ spectrum of $\mathrm{MBN}$ is shown in Fig. $2 \mathrm{~d}$.

\section{Methods}

Mass loss measurements

Mass loss measurements were performed by weighing cleaned and dried MS specimens before and after immersion in $0.5 \mathrm{M} \mathrm{HCl}$ solutions from 1 to $5 \mathrm{~h}$ in the absence and presence of various concentrations of PMN, MMN, NBT and MBN at different temperatures $\left(30-60{ }^{\circ} \mathrm{C}\right)$. Triplicate experiments were performed in each case and the mean value of the mass loss was noted. Corrosion rate $\left(C_{\mathrm{R}}\right)$ in $\mathrm{mg} \mathrm{cm}^{-2} \mathrm{~h}^{-1}$ and inhibition efficiency IE $(\%)$ were calculated using the following equations:

$C_{\mathrm{R}}=\frac{\Delta M}{S t}$

where $\Delta M$ is the mass loss, $S$ is the surface area of the specimen and $t$ is the immersion time.

$\operatorname{IE}(\%)=\frac{\left(C_{\mathrm{R}}\right)_{\mathrm{a}}-\left(C_{\mathrm{R}}\right)_{\mathrm{p}}}{\left(C_{\mathrm{R}}\right)_{\mathrm{a}}} \times 100$

where $\left(C_{\mathrm{R}}\right)_{\mathrm{a}}$ and $\left(C_{\mathrm{R}}\right)_{\mathrm{p}}$ are the corrosion rates in the absence and presence of inhibitor, respectively. 

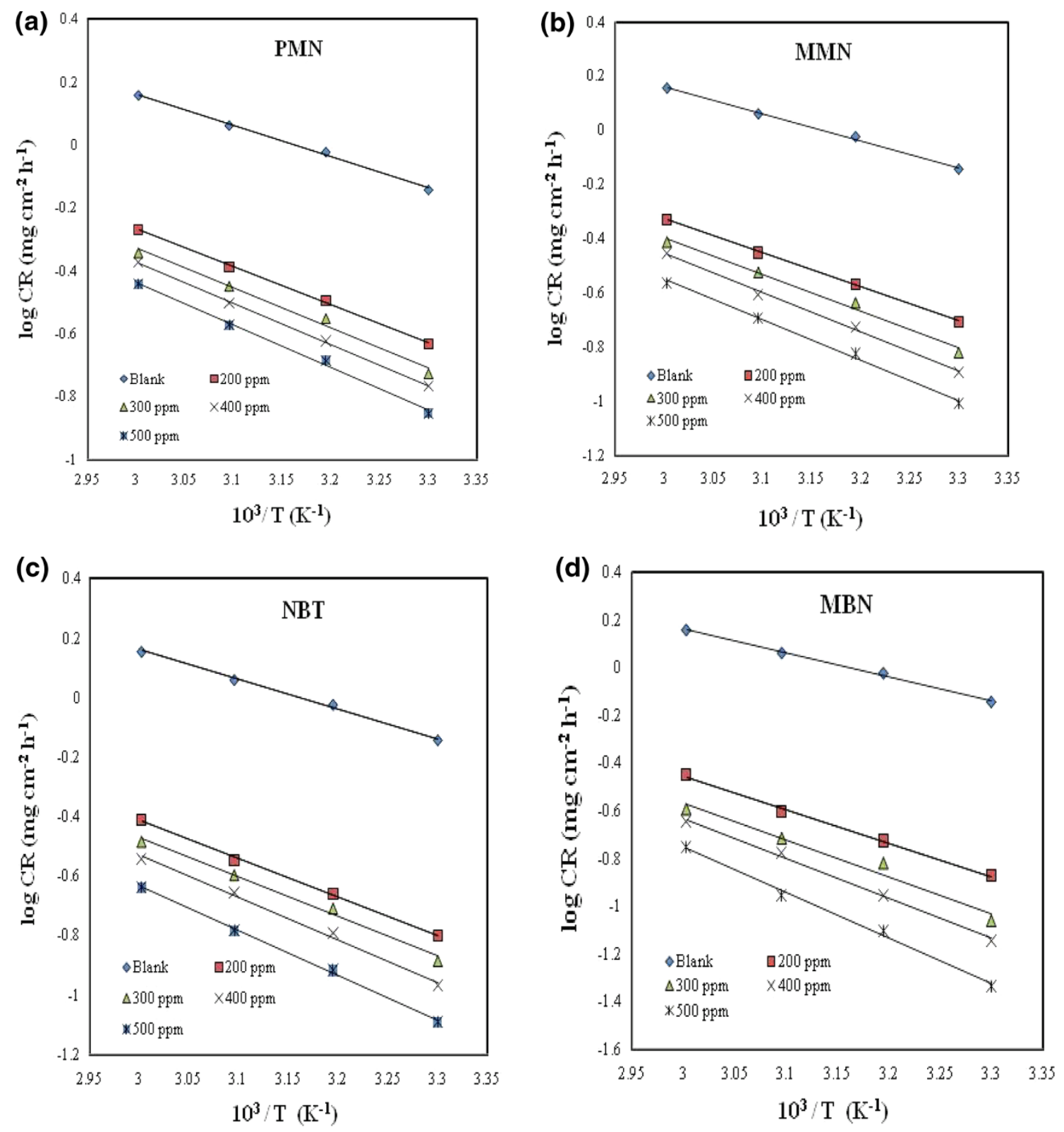

Fig. 3 Plot of $\log C_{\mathrm{R}}$ versus $1 / T$ for a PMN, b MMN, c NBT and d MBN

Potentiodynamic polarization measurements

The potentiodynamic polarization studies were carried out with MS specimen as working electrode in $0.5 \mathrm{M} \mathrm{HCl}$ solutions with different inhibitor's concentrations (200$500 \mathrm{ppm}$ ) with an exposed area of $1 \mathrm{~cm}^{2}$ and this working area was remained precisely fixed throughout the experiment. A conventional three electrode cell consisting of MS as working electrode, platinum foil as counter electrode and saturated calomel electrode (SCE) as reference electrode was used. Potentiodynamic polarization studies were carried out using CH-instrument (model CHI660D). Before each Tafel experiment, the MS electrode was allowed to corrode freely and its open circuit potential (OCP) was recorded as a function of time up to $30 \mathrm{~min}$. After this time, a steady state OCP corresponding to the corrosion potential $\left(E_{\text {corr }}\right)$ of the working electrode was obtained. The IE $(\%)$ was calculated from corrosion currents determined from the Tafel extrapolation plot method using the experimental relation:

IE $(\%)=\frac{\left(I_{\text {corr }}\right)_{\mathrm{a}}-\left(I_{\text {corr }}\right)_{\mathrm{p}}}{\left(I_{\text {corr }}\right)_{\mathrm{a}}} \times 100$

where $\left(I_{\text {corr }}\right)_{\mathrm{a}}$ and $\left(I_{\text {corr }}\right)_{\mathrm{p}}$ are the corrosion current density $\left(\mu \mathrm{A} \mathrm{cm}{ }^{-2}\right)$ in the absence and presence of the inhibitor, respectively. 
Table 2 Values of activation parameters for MS in $0.5 \mathrm{M}$ $\mathrm{HCl}$ medium in the absence and presence of various concentrations of PMN, MMN, NBT and MBN

\begin{tabular}{lcllll}
\hline Inhibitor & $C(\mathrm{ppm})$ & $E_{\mathrm{a}}\left(\mathrm{kJ} \mathrm{mol}^{-1}\right)$ & $\Delta H_{\mathrm{a}}\left(\mathrm{kJ} \mathrm{mol}^{-1}\right)$ & $\Delta H_{\mathrm{a}}=E_{\mathrm{a}}-R T\left(\mathrm{~kJ} \mathrm{~mol}^{-1}\right)$ & $\Delta S_{\mathrm{a}}\left(\mathrm{J} \mathrm{mol}^{-1} \mathrm{~K}^{-1}\right)$ \\
\hline Blank & 0 & 19.0 & 16.4 & 16.5 & -197.6 \\
PMN & 200 & 23.2 & 20.5 & 20.6 & -189.4 \\
& 300 & 24.4 & 21.7 & 21.8 & -186.9 \\
& 400 & 25.0 & 22.4 & 22.5 & -185.7 \\
& 500 & 26.0 & 23.3 & 23.5 & -184.1 \\
MMN & 200 & 24.0 & 21.3 & 21.5 & -188.0 \\
& 300 & 25.7 & 23.0 & 23.1 & -184.3 \\
& 400 & 27.5 & 24.8 & 24.9 & -180.1 \\
& 500 & 28.3 & 25.6 & 25.8 & -179.5 \\
NBT & 200 & 24.9 & 22.2 & 22.4 & -187.0 \\
& 300 & 25.3 & 22.7 & 22.8 & -186.8 \\
& 400 & 27.4 & 24.8 & 24.9 & -181.6 \\
& 500 & 28.8 & 26.1 & 26.2 & -181.9 \\
MBN & 200 & 26.9 & 24.2 & 24.3 & -176.8 \\
& 300 & 29.3 & 26.6 & 26.8 & -169.3 \\
& 400 & 32.2 & 29.5 & 29.7 & -158.6 \\
& 500 & 36.5 & 33.9 & 34.0 & \\
\hline
\end{tabular}

Electrochemical impedance spectroscopy (EIS)

Electrochemical impedance spectroscopy measurements were carried out using the same $\mathrm{CH}$-instrument. The EIS data were taken in the frequency range $10-0.05 \mathrm{kHz}$. The double layer capacitance $\left(C_{\mathrm{dl}}\right)$ and the polarization resistance $\left(R_{\mathrm{p}}\right)$ were determined from Nyquist plots [29]. The percentage inhibition efficiency, IE (\%) was calculated from $R_{\mathrm{p}}$ values using the following expression:

$\operatorname{IE}(\%)=\frac{1 /\left(R_{\mathrm{p}}\right)_{\mathrm{a}}-1 /\left(R_{\mathrm{p}}\right)_{p}}{1 /\left(R_{\mathrm{p}}\right)_{\mathrm{a}}} \times 100$

where $\left(R_{\mathrm{p}}\right)_{\mathrm{a}}$ and $\left(R_{\mathrm{p}}\right)_{\mathrm{p}}$ are polarization resistances in the absence and presence of inhibitor, respectively.

\section{FTIR, EDX and SEM studies}

The MS specimens were immersed in $0.5 \mathrm{M} \mathrm{HCl}$ in the presence of inhibitors $(500 \mathrm{ppm})$ for a period of $1 \mathrm{~h}$. Then the specimens were taken out and dried. The surface adhered film was scratched carefully and its FTIR spectra were recorded using a Jasco FTIR 4100 double beam spectrophotometer. The surface feature of the MS specimens in the absence and presence of inhibitors was studied by energy dispersive X-ray spectroscopy (EDX) and scanning electron microscope (model JSM-5800).

Characterization of inhibitors

Melting range was determined by Veego Melting Point VMP III apparatus. FTIR spectra were recorded using a
Jasco FTIR 4100 double beam spectrophotometer. ${ }^{1} \mathrm{H}$ NMR spectra were recorded on Bruker DRX-500 spectrometer at $400 \mathrm{MHz}$ using DMSO- $\mathrm{d}_{6}$ as solvent and TMS as an internal standard. Mass spectral data were obtained by LC/MSD Trap XCT. Elemental analyses were recorded on VarioMICRO superuser V1.3.2 Elementar.

\section{Results and discussion}

Mass loss studies

The $C_{\mathrm{R}}$ and IE $(\%)$ in the absence and presence of various concentrations of PMN, MMN, NBT and $\mathrm{MBN}$ in $0.5 \mathrm{M}$ $\mathrm{HCl}$ solution and at different temperatures $\left(30-60{ }^{\circ} \mathrm{C}\right)$ are presented in Table 1. The mass loss was found to be decreased and IE (\%) observed to be increased with increase in concentration of nicotinamide derivatives. The studied inhibitors were found to attain the maximum inhibition efficiency at 500 ppm. Further increase in concentration (beyond $500 \mathrm{ppm}$ ) did not cause any remarkable change in the inhibition efficiency. This conclusion is also supported by electrochemical studies. There is no appreciable increase in the inhibition efficiency after $1 \mathrm{~h}$ of immersion time, this is due to desorption of the inhibitor molecules from the metal surface with increasing immersion time and instability of the inhibitor film on the metal surface [30, 31]. The IE $(\%)$ of nicotinamide derivatives follows the order: $\mathrm{MBN}>\mathrm{NBT}>\mathrm{MMN}>\mathrm{PMN}$. The inhibition efficiency obtained from weight loss measurements is lower than that for electrochemical experiments, this phenomenon attributed to the fact that the weight loss 

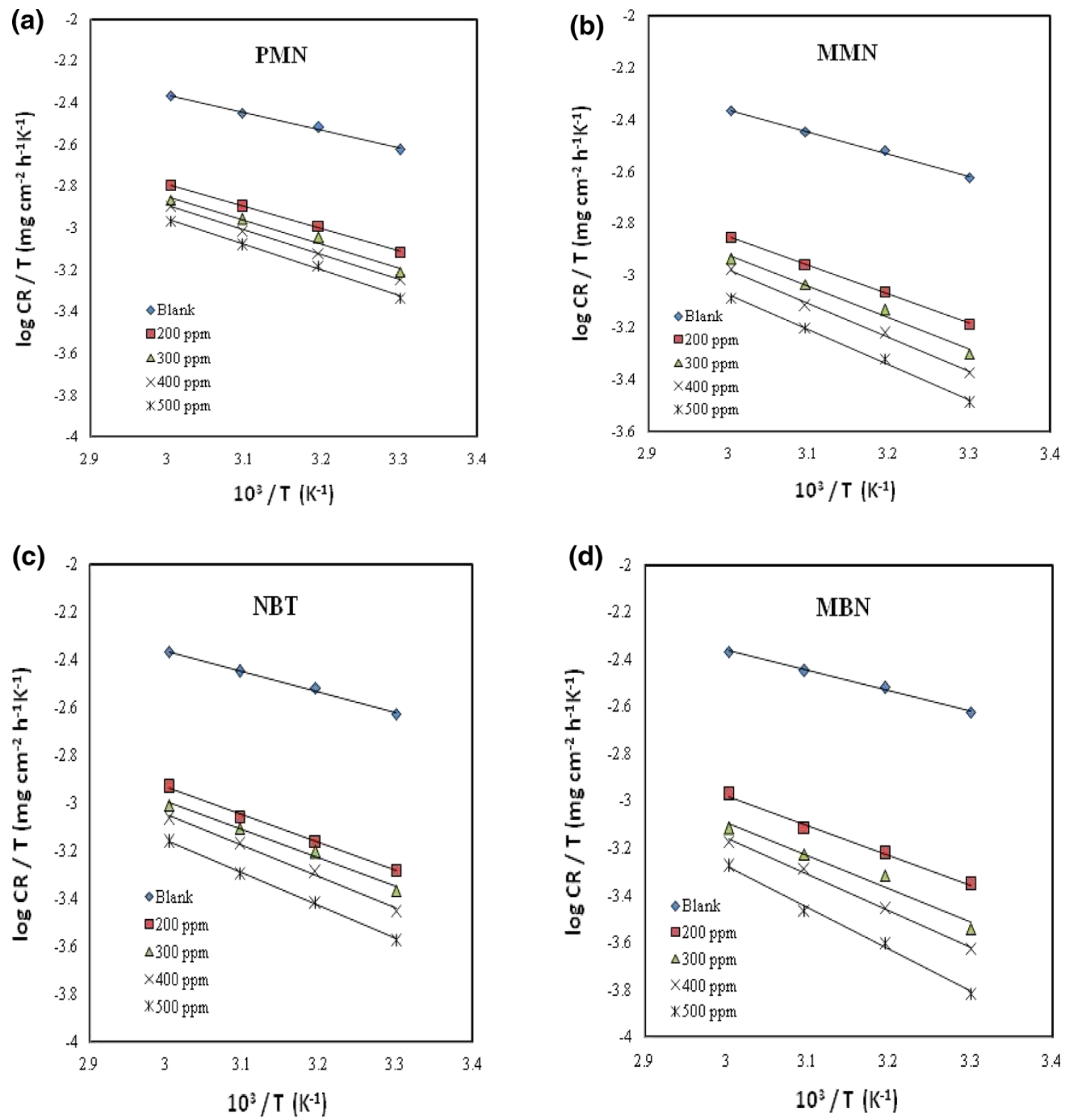

Fig. 4 Alternative Arrhenius plots for MS dissolution in $0.5 \mathrm{M} \mathrm{HCl}$ medium in the absence and presence of a PMN, b MMN, c NBT and d MBN

experiment gives average corrosion rates whereas the electrochemical experiments give instantaneous corrosion rates.

\section{Effect of temperature}

The effect of temperature on $C_{\mathrm{R}}$ and IE (\%) was studied in $0.5 \mathrm{M} \mathrm{HCl}$ in the temperature range of $30-60{ }^{\circ} \mathrm{C}$ in the absence and presence of different concentrations of inhibitors (Table 1). The inhibition efficiencies were found to decrease with increasing temperature from 30 to $60{ }^{\circ} \mathrm{C}$.
This may be explained with desorption of adsorbed inhibitor molecules on the MS surface. This proves that the inhibition occurs through the adsorption of the inhibitors on the metal surface, and desorption is aided by increasing temperature. The activation parameters for the corrosion process were calculated from the Arrhenius type plot according to the following equation:

$C_{\mathrm{R}}=\operatorname{kexp}^{-E_{\mathrm{a}} / R T}$

where $E_{\mathrm{a}}$ is the activation energy, $k$ is the frequency factor, $T$ is the absolute temperature and $R$ is the universal gas constant. The values of $E_{\mathrm{a}}$ for $\mathrm{MS}$ in $0.5 \mathrm{M} \mathrm{HCl}$ without 

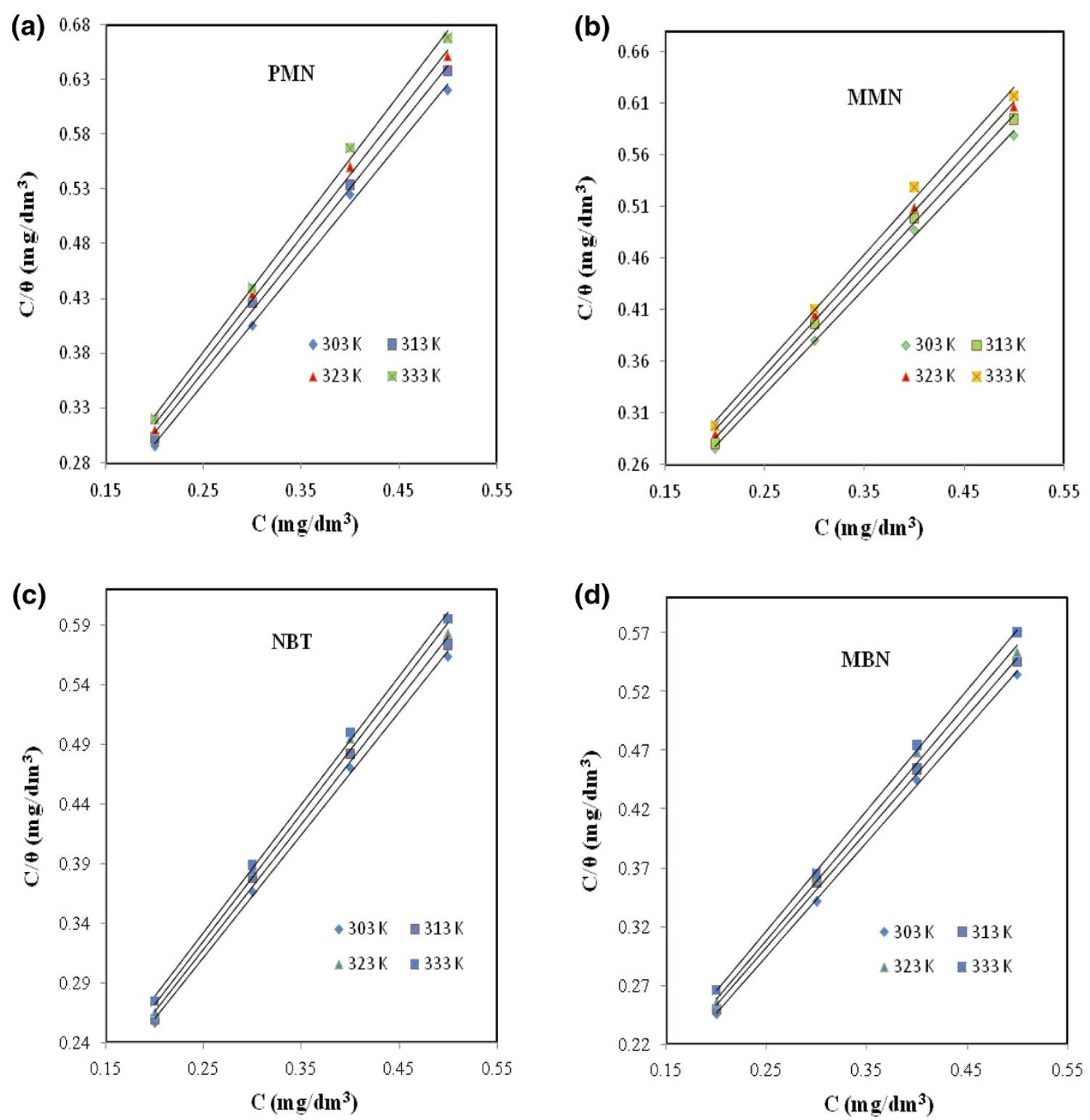

Fig. 5 Langmuir's adsorption isotherm plots for the adsorption of a PMN, b MMN, c NBT and d MBN in $0.5 \mathrm{M} \mathrm{HCl}$ on MS surface at different temperature

and with various concentrations of inhibitors were obtained from the slope of the plot of $\log C_{\mathrm{R}}$ versus $1 / T$ (Fig. 3) and are shown in Table 2. It was found that $E_{\mathrm{a}}$ values for inhibited systems are higher than those for the uninhibited systems (Table 2). This increase in the activation energy decreases the corrosion rate of metal [32]. With increasing temperature there is an appreciable decrease in the adsorption of the inhibitors on the metal surface and a corresponding rise in the corrosion rate occurred.

An alternative Arrhenius plots of $\log C_{\mathrm{R}} / T$ versus $1 / T$ (Fig. 4) for MS dissolution in $0.5 \mathrm{M} \mathrm{HCl}$ medium in the absence and presence of different concentrations of PMN, MMN, NBT and MBN were used to calculate the values of activation thermodynamic parameters such as enthalpy of activation $\left(\Delta H_{\mathrm{a}}\right)$ and entropy of activation $\left(\Delta S_{\mathrm{a}}\right)$ using the relation (6),

$C_{\mathrm{R}}=\frac{R T}{N h} \exp \left(\frac{\Delta S_{\mathrm{a}}}{R}\right) \exp \left(\frac{-\Delta H_{\mathrm{a}}}{R T}\right)$

where $R$ is the universal gas constant, $T$ is the absolute temperature, $N$ is the Avogadro's number, $h$ is Planks constant. The values of $\Delta H_{\mathrm{a}}$ and $\Delta S_{\mathrm{a}}$ were obtained from the slope and intercept of the above plot, and presented in Table 2. The obtained $\Delta H_{\mathrm{a}}$ values are in good agreement with the calculated $\Delta H_{\mathrm{a}}$ from the equation, $\Delta H_{\mathrm{a}}=E_{\mathrm{a}}-R T$. 


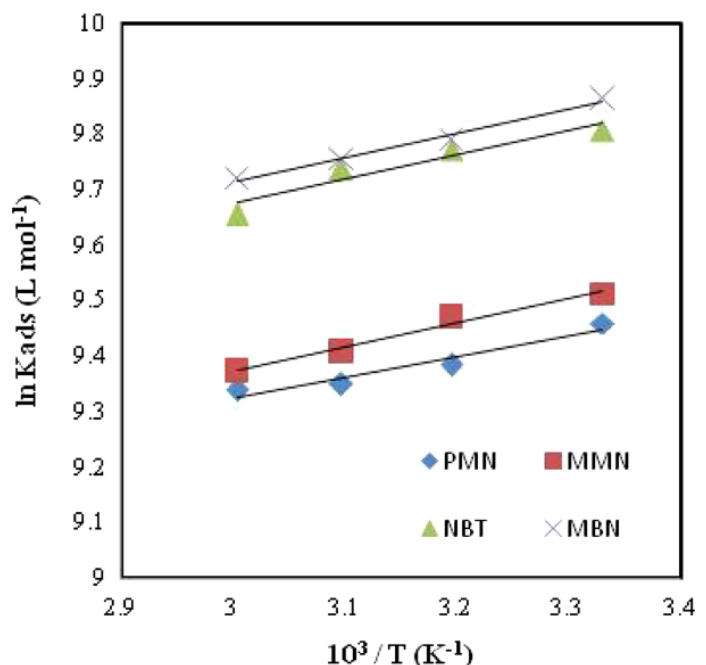

Fig. 6 Plot of $\ln K_{\text {ads }}$ versus $1 / T$ for PMN, MMN, NBT and MBN

The positive values of enthalpy of activation in the absence and presence of inhibitors indicate an endothermic nature of MS dissolution process [33], and increase in the entropy of activation values decreases in the system disorder due to the adsorption of inhibitor molecules on the MS surface [34-36].

\section{Adsorption isotherm}

The efficiency of a corrosion inhibitor mainly depends on its adsorption ability on the metal surface. So, it is necessary to know the mechanism of adsorption and the adsorption isotherm that can give valuable information on the interaction of inhibitor and metal surface. The adsorption of inhibitor molecules from aqueous solution is a quasi-substitution process, and was found to be highly $\mathrm{pH}$ dependent [37]. The surface protection of MS depends upon how the inhibitor molecule will adsorbed on the metal surface, and also ionization and polarization of molecule [38]. The degree of surface coverage $(\theta)$ as function of concentration $(C)$ of the inhibitor was studied graphically by fitting it to various adsorption isotherms to find the best adsorption isotherm. The Langmuir adsorption isotherm model was taken into account since equilibrium adsorption of all the four inhibitors was found to obey this adsorption isotherm model on MS in $0.5 \mathrm{M} \mathrm{HCl}$ medium. According to this adsorption isotherm, $\theta$ is related to the inhibitor concentration, $C$ and adsorption equilibrium constant $K_{\text {ads }}$ through the following expression:

$C / \theta=\frac{1}{K_{\mathrm{ads}}}+C$

The surface coverage was tested graphically for fitting a suitable adsorption isotherm. In the present case, the plots of $C / \theta$ versus $C$ (Fig. 5) yield straight lines with the linear correlation coefficient $\left(R^{2}\right)$ values close to unity, which suggests that the adsorption of PMN, MMN, NBT and MBN in $0.5 \mathrm{M} \mathrm{HCl}$ medium on MS surface obeys the Langmuir adsorption isotherm. The Gibbs free energy of adsorption was calculated using the relation (8):

$\Delta G_{\mathrm{ads}}^{\circ}=-2.303 R T \log 55.5 K_{\mathrm{ads}}$

where $R$ is the universal gas constant, $T$ is the absolute temperature, $K_{\text {ads }}$ is the equilibrium constant for adsorption-desorption process and 55.5 is the molar concentration
Table 3 Thermodynamic parameters for adsorption of PMN, MMN, NBT and MBN on MS in $0.5 \mathrm{M} \mathrm{HCl}$ at different temperatures

\begin{tabular}{lllllll}
\hline Inhibitor & $T\left({ }^{\circ} \mathrm{C}\right)$ & $R^{2}$ & $\begin{array}{l}K_{\mathrm{ads}} \\
\left(\mathrm{L} \mathrm{mol}^{-1}\right)\end{array}$ & $\begin{array}{l}\Delta G_{\mathrm{ads}}^{\circ} \\
\left(\mathrm{kJ} \mathrm{mol}^{-1}\right)\end{array}$ & $\begin{array}{l}\Delta H_{\mathrm{ads}}^{\circ} \\
\left(\mathrm{kJ} \mathrm{mol}^{-1}\right)\end{array}$ & $\begin{array}{l}\Delta S_{\mathrm{ads}}^{\circ} \\
\left(\mathrm{J} \mathrm{mol}^{-1} \mathrm{~K}^{-1}\right)\end{array}$ \\
\hline PMN & 30 & 0.998 & 12,820 & -33.95 & & \\
& 40 & 0.998 & 11,904 & -34.87 & 0.376 & \\
& 50 & 0.998 & 11,494 & -35.89 & & \\
& 60 & 0.997 & 11,363 & -36.97 & & \\
MMN & 30 & 0.999 & 13,513 & -34.08 & & \\
& 40 & 0.997 & 12,987 & -35.10 & 0.438 & \\
& 50 & 0.998 & 12,195 & -36.05 & & \\
& 60 & 0.996 & 11,764 & -37.07 & & \\
NBT & 30 & 0.998 & 18,181 & -34.83 & & \\
& 40 & 0.996 & 17,543 & -35.88 & 0.442 & \\
& 50 & 0.995 & 16,949 & -36.94 & & \\
& 60 & 0.998 & 15,625 & -37.86 & & \\
MBN & 30 & 0.999 & 19,230 & -34.97 & & \\
& 40 & 0.998 & 17,857 & -35.93 & 0.434 & \\
& 50 & 0.997 & 17,241 & -36.98 & & \\
& 60 & 0.999 & 16,666 & -38.04 & & \\
& & & & & & \\
\end{tabular}



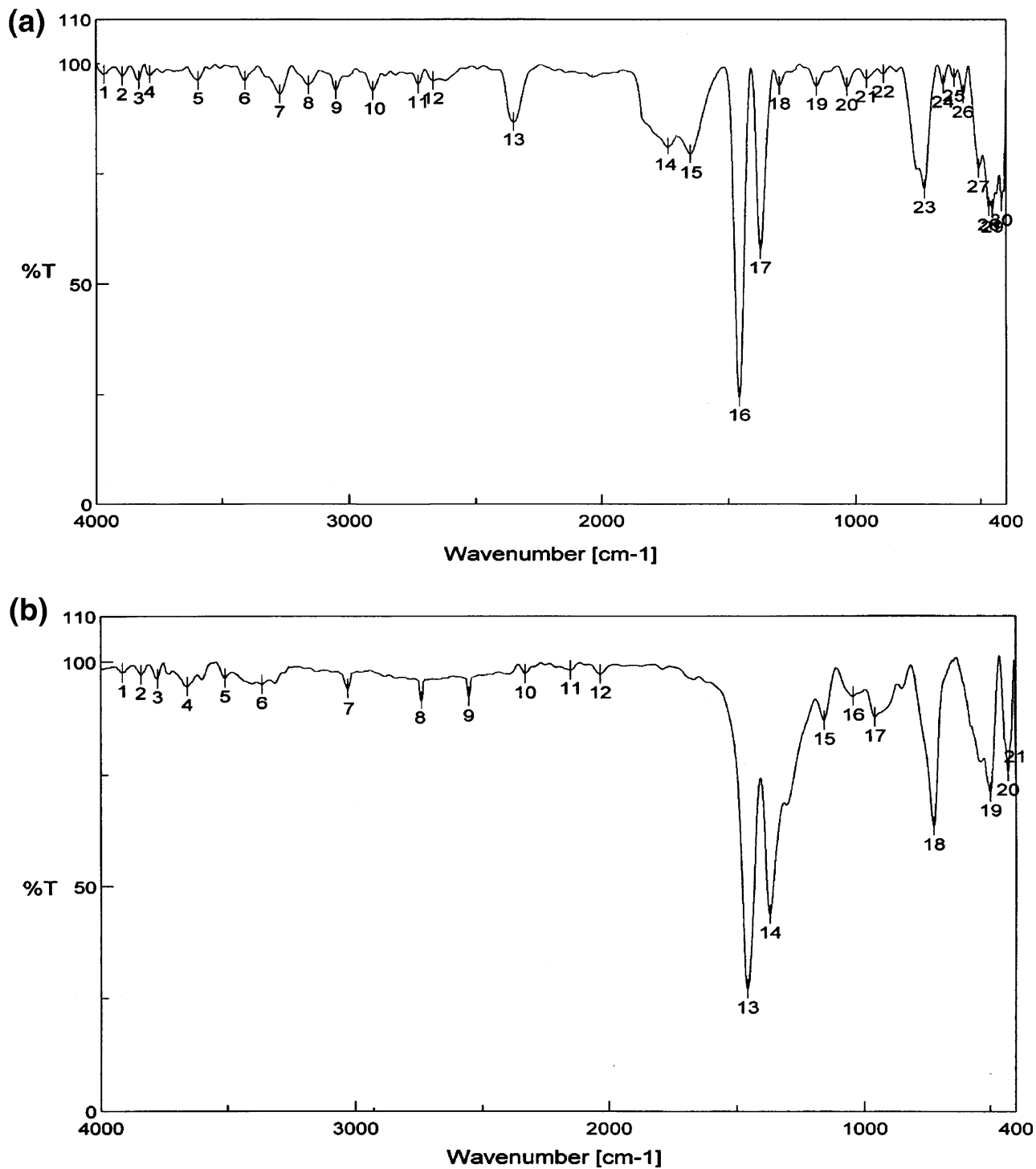

Fig. 7 FTIR spectra of a PMN and b scratched MS surface adsorbed PMN film

of water in solution $\left(\mathrm{mol} \mathrm{L}^{-1}\right)$. The other adsorption thermodynamic parameters such as enthalpy of adsorption $\left(\Delta H_{\mathrm{ads}}^{\circ}\right)$ and entropy of adsorption $\left(\Delta S_{\mathrm{ads}}^{\circ}\right)$ were obtained from the slope and intercept of the plot of $\log K_{\text {ads }}$ versus 1/T (Fig. 6) using the Eq. (9).

$\log K_{\mathrm{ads}}=\frac{1}{2.303}\left(-\frac{\Delta H_{\mathrm{ads}}^{\circ}}{R T}\right)+\left(\frac{\Delta S_{\mathrm{ads}}^{\circ}}{R}\right)$

The calculated values of $K_{\text {ads }}, \Delta H_{\text {ads }}^{\circ}, \Delta G_{\text {ads }}^{\circ}$ and $\Delta S_{\text {ads }}^{\circ}$ over the temperature range of $30-60{ }^{\circ} \mathrm{C}$ are recorded in Table 3. The negative values of $\Delta G_{\text {ads }}^{\circ}$ indicate the spontaneous adsorption of inhibitors on the surface of MS [39]. In the present study, $\Delta G_{\text {ads }}^{\circ}$ values for PMN, MMN, NBT and MBN are found to be in the range -33.95 to -36.97 , -34.08 to $-37.07,-34.83$ to -37.86 and -34.97 to
$-38.04 \mathrm{~kJ} \mathrm{~mol}^{-1}$ in the temperature range of $30-60{ }^{\circ} \mathrm{C}$, respectively indicating that the adsorption is the combination of both physisorption and chemisorption [40-43].

FTIR spectral studies

FTIR spectra were recorded to understand the interaction of inhibitor molecules with the metal surface. Figures 7a, 8a, 9a and 10a show the FTIR spectra of pure PMN, MMN, NBT and MBN, and Figs. 7b, 8b, 9b and $10 \mathrm{~b}$ represent the FTIR spectra of the scrapped samples obtained from the metal surfaces after corrosion experiments. It was found that peaks in the spectrum of scrapped samples were changed when compared to pure compounds. The azomethine group stretching frequencies for pure PMN, MMN, 
Fig. 8 FTIR spectra of a MMN and $\mathbf{b}$ scratched MS surface adsorbed MMN film
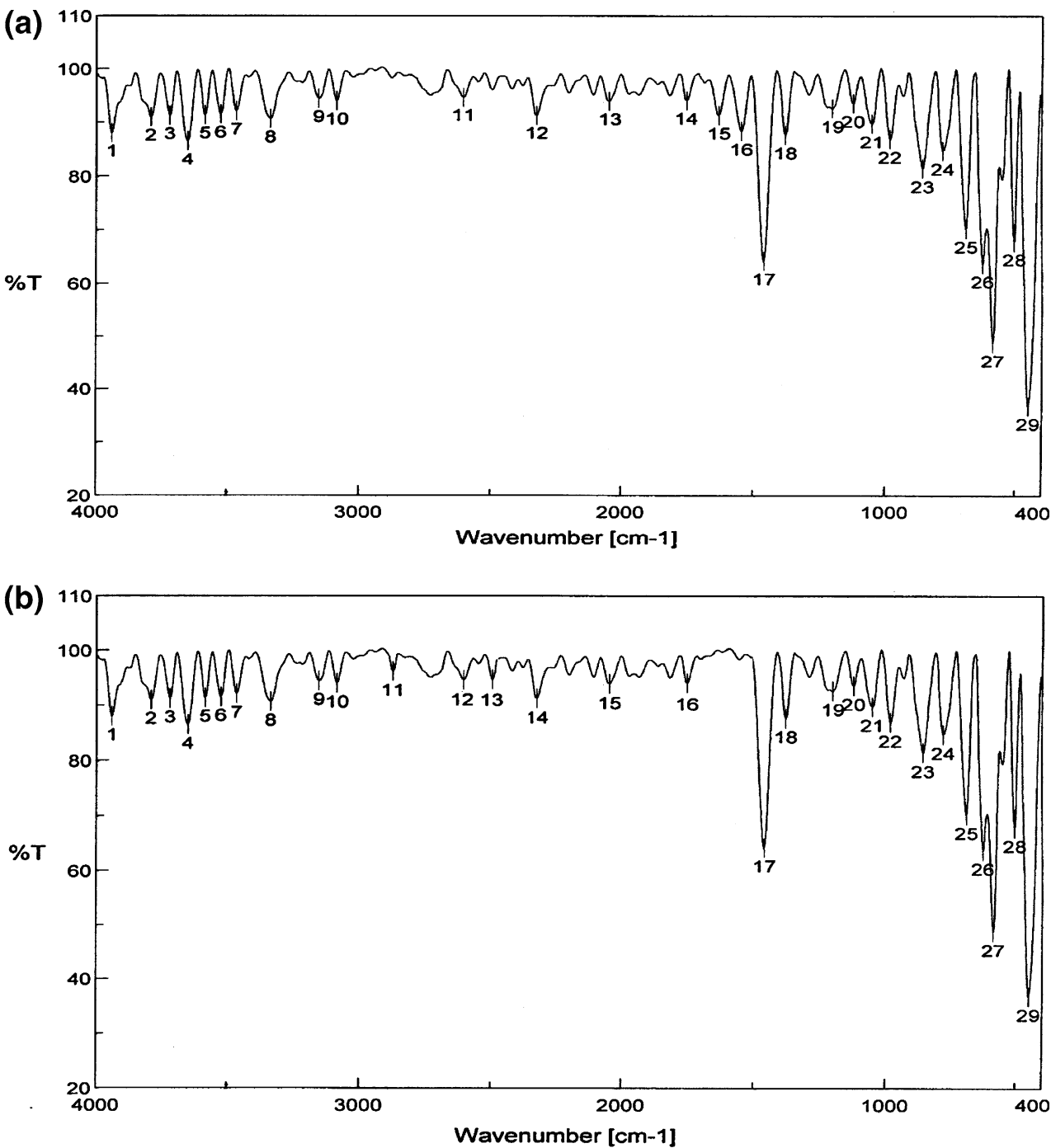

NBT and MBN were found at 1,645, 1,630, 1,643 and $1,587 \mathrm{~cm}^{-1}$, and carbonyl stretching frequencies were observed at 1,726, 1,672,1,726 and $1,697 \mathrm{~cm}^{-1}$, respectively. In the FTIR spectra of scrapped samples, the stretching frequencies of the azomethine and carbonyl groups were found to be disappeared in the case of PMN, MMN and MBN, but in the case of NBT azomethine group was also disappeared and carbonyl stretching frequency was found to be slightly shifted to lower frequency $\left(1,689 \mathrm{~cm}^{-1}\right)$. These observations confirm that the azomethine and carbonyl groups of PMN, MMN, NBT and MBN are involved in the complex formation with the metal.
Potentiodynamic polarization studies

Polarization measurements were carried out to know the kinetics of anodic and cathodic reactions. Figure 11 reveals the polarization curves for $\mathrm{MS}$ in $0.5 \mathrm{M} \mathrm{HCl}$ in the absence and presence of different concentrations of PMN, MMN, NBT and MBN at $30{ }^{\circ} \mathrm{C}$. Inspection of Tafel extrapolation plots showed that the addition of inhibitors hindered the acid attack on the MS electrode. In all the cases, the addition of inhibitors reduces both anodic and cathodic current densities indicating that these inhibitors exhibit cathodic and anodic inhibition effects, hence they are relatively mixed type of inhibitors [44, 45]. 
Fig. 9 FTIR spectra of a NBT and $\mathbf{b}$ scratched MS surface adsorbed NBT film
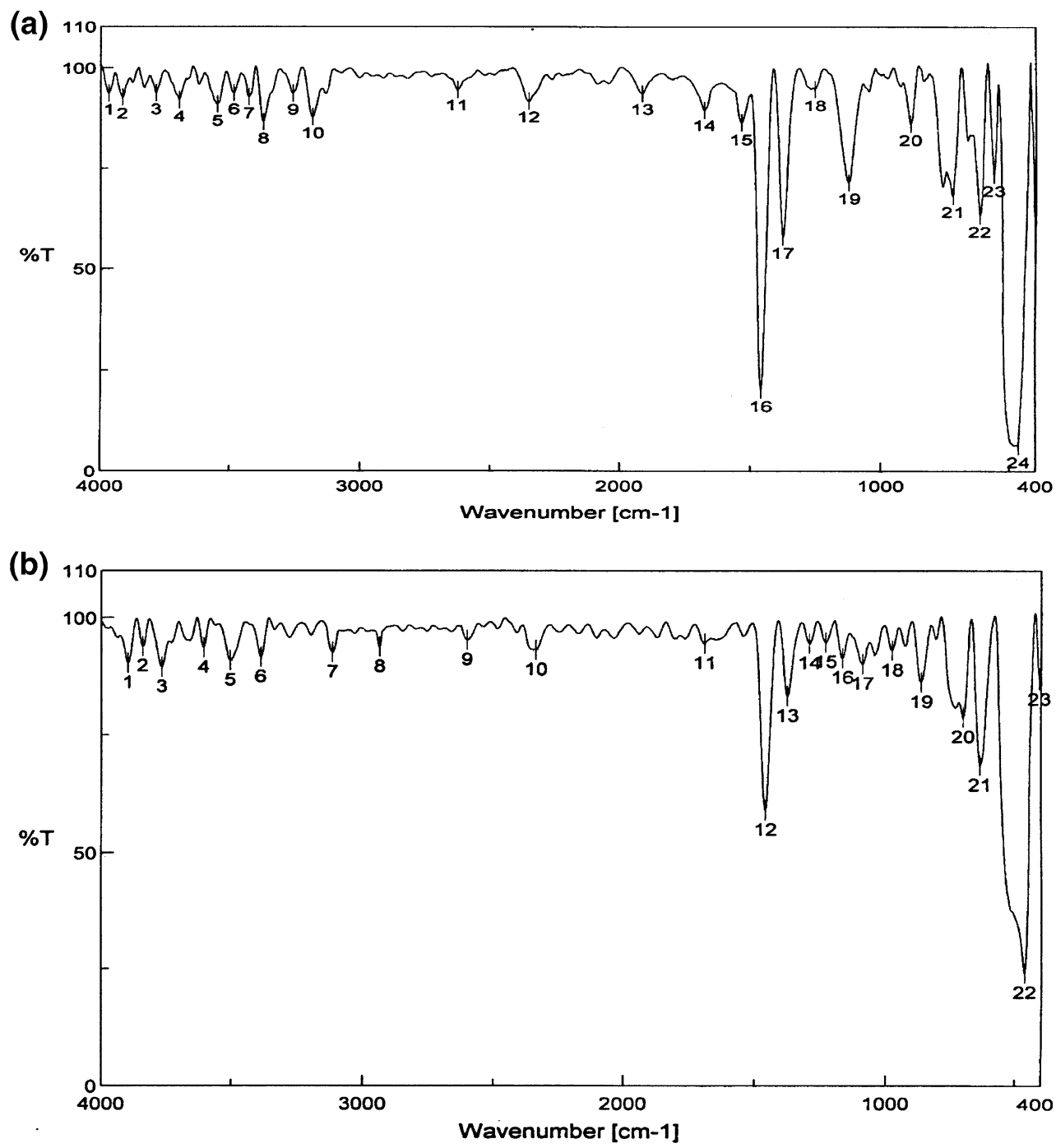

As the corrosion current density decreases, there will be a corresponding decrease in the electron transfer in the redox process; therefore the rate of corrosion reaction becomes slower. Usually a very good corrosion protection can be seen at low current density and at long anodization time due to the diminution of the porosity of the anodic films formed. Table 4 clearly highlights that there is a gradual decrease in the corrosion potential and corrosion current values as the inhibitor concentration was raised from 200 to $500 \mathrm{ppm}$. The values associated with electrochemical polarization parameters such as corrosion current density $\left(I_{\text {corr }}\right)$, corrosion potential $\left(E_{\text {corr }}\right)$, corrosion rate and IE (\%) were determined from the polarization plots, and are given in Table 4. The values of corrosion current densities were obtained by extrapolating the current-potential lines to the corresponding corrosion potentials. It is evident that IE (\%) increases with inhibitors concentration, and protection action of PMN, MMN, NBT and $\mathrm{MBN}$ can be attributed to the electron density of the azomethine $(-\mathrm{C}=\mathrm{N}-)$ group and this electron density varies with the substituent's in the inhibitor molecules. The imine nitrogen can donate the lone pair of electrons to the metal surface more easily and hence reduces the corrosion rate. The IE (\%) was found to be in the order: $\mathrm{MBN}>\mathrm{NBT}>\mathrm{MMN}>\mathrm{PMN}$, which can probably be explained on the basis of additional functional groups and also the nature of the hetero atoms in the inhibitor molecules. 
Fig. 10 FTIR spectra of a MBN and b scratched MS surface adsorbed MBN film
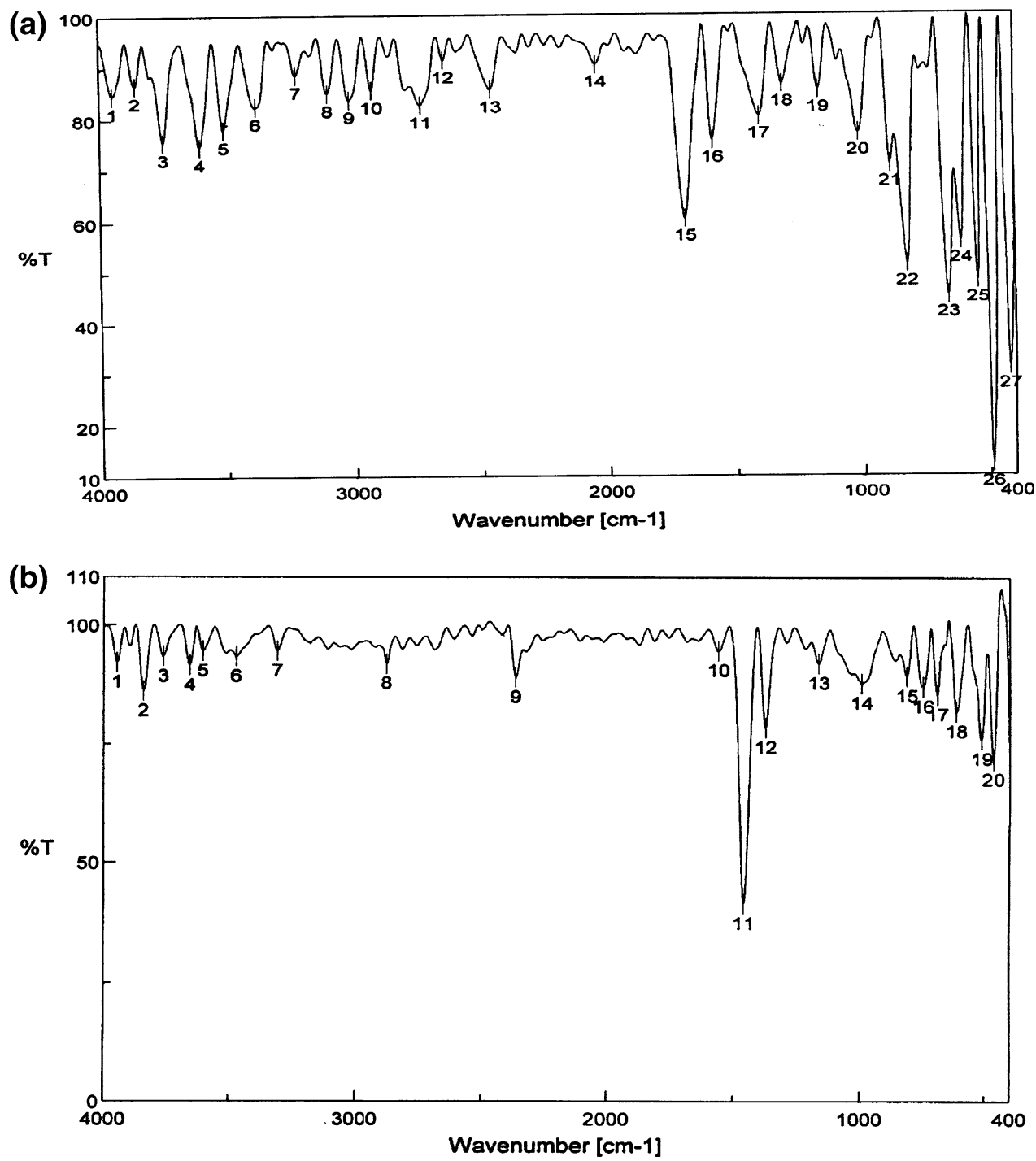

\section{Electrochemical impedance spectroscopy}

Nyquist plots for $\mathrm{MS}$ in $0.5 \mathrm{M} \mathrm{HCl}$ solution with and without different concentrations of PMN, MMN, NBT and MBN are presented in Fig. 12. The Nyquist plots were regarded as one part of the semicircle mostly referred to as frequency dispersion which could be attributed to different physical phenomenon such as roughness, heterogeneities, impurities, grain boundaries and distribution of the surface active sites [46]. The electrochemical impedance parameters derived from the Nyquist plots and IE (\%) are listed in Table 5. From the plots, it was clear that the impedance response of MS in uninhibited acid solution has significantly changed after the addition of inhibitors to the corrosive solution. This indicates that the impedance of the inhibited metal has increased with increasing concentration of inhibitors. The measured impedance data were based upon the equivalent circuit, given in the Fig. 13, which consists of constant double layer capacitance $\left(C_{\mathrm{dl}}\right)$ in parallel with polarization resistance $\left(R_{\mathrm{p}}\right)$ which is in series with solution resistance $\left(R_{\mathrm{S}}\right)$.

It was observable that, $R_{\mathrm{p}}$ values in the absence of the inhibitors were always lower than those in the presence of the inhibitors. The increase in the $R_{\mathrm{p}}$ values in the presence of different concentrations of PMN, MMN, NBT and MBN indicates reduction in the MS corrosion rate with the 

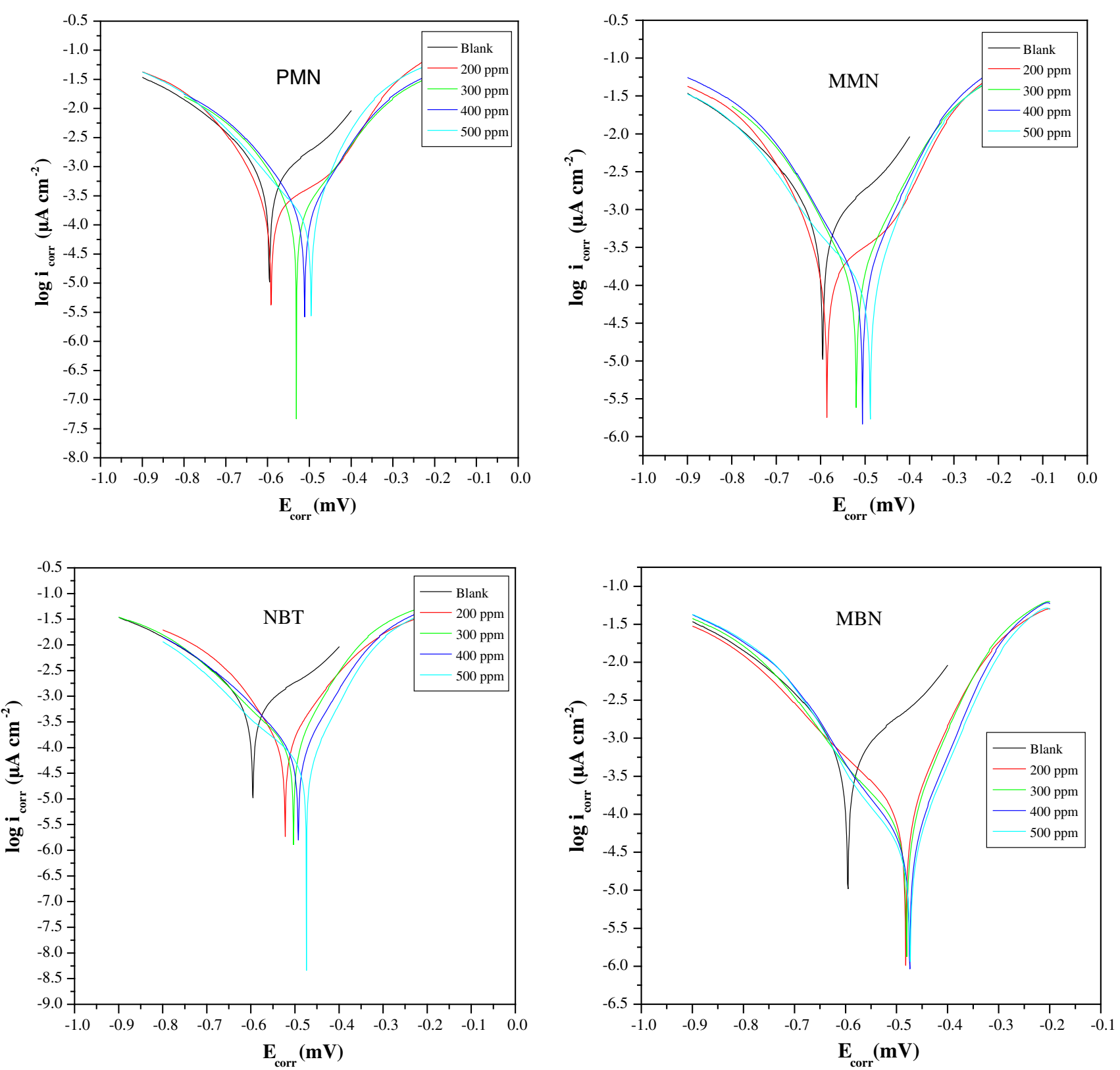

Fig. 11 Polarization curves of MS in $0.5 \mathrm{M} \mathrm{HCl}$ in the presence of different concentrations of PMN, MMN, NBT and MBN

formation of adsorbed protective film on the metal-solution interface $[47,48]$. When the concentration was raised from 200 to $500 \mathrm{ppm}$, there was a gradual increase in the diameter of each semicircle of the Nyquist plot reflecting the increase in $R_{\mathrm{p}}$ values from 27.81 to $163.8,190.5,316.8$ and $562.0 \Omega \mathrm{cm}^{2}$ for PMN, MMN, NBT and MBN, respectively which indicates the adsorption of inhibitor molecules on the metal surface and also increase in stability of inhibitors film adsorbed on the metal surface.
The double layer capacitance $\left(C_{\mathrm{dl}}\right)$ values were decreased due to decrease in local dielectric constant and/ or an increase in the thickness of the electrical double layer, indicating that the inhibitor molecules adsorbed at the metal-solution interface $[49,50]$. Decrease in the surface area [51] and imperfections of the metal surface may also be the reason for decrease of $C_{\mathrm{dl}}$ values. Addition of inhibitors provided lower $C_{\mathrm{dl}}$ values because of the replacement of water molecules by inhibitor molecules at 
Table 4 Polarization parameters and corresponding inhibition efficiency (IE) for the corrosion of the MS in $0.5 \mathrm{M} \mathrm{HCl}$ without and with various concentrations of PMN, MMN, NBT and MBN

\begin{tabular}{lclll}
\hline Inhibitor & $C(\mathrm{ppm})$ & $-E_{\text {corr }}(\mathrm{mV})$ & $I_{\text {corr }}\left(\mu \mathrm{A} \mathrm{cm}^{-2}\right)$ & IE $(\%)$ \\
\hline Blank & 0 & 0.595 & 711 & - \\
PMN & 200 & 0.592 & 224 & 68.5 \\
& 300 & 0.531 & 187.1 & 73.7 \\
& 400 & 0.511 & 160.5 & 77.4 \\
& 500 & 0.496 & 114.9 & 83.8 \\
MMN & 200 & 0.586 & 162.4 & 77.1 \\
& 300 & 0.520 & 126.4 & 82.2 \\
& 400 & 0.506 & 120.6 & 83.0 \\
& 500 & 0.488 & 95.26 & 86.6 \\
NBT & 200 & 0.522 & 121.2 & 82.9 \\
& 300 & 0.503 & 113.6 & 84.0 \\
& 400 & 0.492 & 74.15 & 89.6 \\
& 500 & 0.474 & 50.5 & 92.9 \\
MBN & 200 & 0.482 & 102.3 & 85.6 \\
& 300 & 0.480 & 69.42 & 90.2 \\
& 400 & 0.474 & 40.18 & 94.3 \\
& 500 & 0.473 & 31.84 & 95.5 \\
\hline
\end{tabular}

the electrode surface [52]. It was clear that as the immersion time increases the $R_{\mathrm{p}}$ values increase and $C_{\mathrm{d} 1}$ values decrease which indicate the higher protection efficiency as a result of slow adsorption of these inhibitor molecules on to the surface of MS. However, when the immersion time is further enhanced, a sudden decrease in $R_{\mathrm{p}}$ values and increase in $C_{\mathrm{dl}}$ values were observed. This behaviour can be due to the instability of the passive film or desorption of the inhibitor molecules.

\section{Mechanism of inhibition}

The inhibition effect of nicotinamide derivatives towards the corrosion of $\mathrm{MS}$ in $0.5 \mathrm{M} \mathrm{HCl}$ solution may be attributed to the adsorption of these compounds at the metal-solution interface. The principal type of interaction between an organic inhibitor and metal surface is physisorption or chemisorption or both. The adsorption of inhibitor is influenced by the nature of the metal, chemical structure of inhibitors, type of aggressive electrolyte, temperature and the morphology of MS [53, 54]. The values of inhibition efficiency depend essentially on the electron density at the active centre of the inhibitor molecule. The thermodynamic parameters showed that the adsorption of these inhibitors on the MS surface in $0.5 \mathrm{M}$ $\mathrm{HCl}$ solution involves both chemisorption and physisorption. Chemisorption of these inhibitors arises from the donor-acceptor interactions between the free electron pairs of hetero atoms and $\pi$ electrons of multiple bonds as well as phenyl group and vacant $d$ orbitals of iron [55].

The inhibition effect of PMN, MMN, NBT and MBN is due to the interaction of $\pi$-electrons of pyrrole, pyridine and phenyl rings as well as the presence of electron donor groups such as $\mathrm{N}, \mathrm{O}, \mathrm{S}, \mathrm{CH}_{3}$ and $\mathrm{C}=\mathrm{N}$, through which the inhibitors adsorbed on the MS surface forming insoluble, stable and uniform thin film. Greater corrosion inhibition behaviour of compound MBN is linked to the electron donating effect of thiomethyl group attached to aromatic ring, which increases the electron density on the benzene ring. The increasing delocalization electron density in the molecule may be responsible for inhibiting corrosion process. The adsorption of inhibitor molecules is further stabilized by participation of $\pi$-electrons of benzene ring. The good inhibition efficiency of NBT compare to MMN and PMN may be due to the presence of extra thiol ( $\mathrm{SH}$ ) group. MMN (86\%) and PMN (83\%) are structurally almost similar exhibiting comparable corrosion inhibition efficiency at $500 \mathrm{ppm}$. The order of inhibition efficiency of the four inhibitors from mass loss, potentiodynamic polarization and EIS studies was found to be: $\mathrm{MBN}>\mathrm{NBT}>$ MMN > PMN.

\section{EDX analysis}

EDX spectra were used to determine the elements present on MS surface before and after exposure to the inhibitor solution. The results are displayed in Fig. 14. Figure 14a is the EDX spectrum of polished MS sample and it is notable that the peak of oxygen is absent which confirms the absence of air formed oxide film. However, for inhibited solutions (Fig. 14b-e) the additional lines characteristics for the existence of $\mathrm{N}, \mathrm{O}$ and $\mathrm{S}$ (due to the $\mathrm{N}$ and $\mathrm{O}$ atoms of the PMN and MMN, N, O and S atoms of the NBT and $\mathrm{MBN}$ ) in the EDX spectra were obtained. These data showed that the $\mathrm{N}, \mathrm{O}$ and $\mathrm{S}$ atoms of inhibitors are involved in bonding with the MS electrode surface. These results confirm those obtained from IR and SEM observations. 

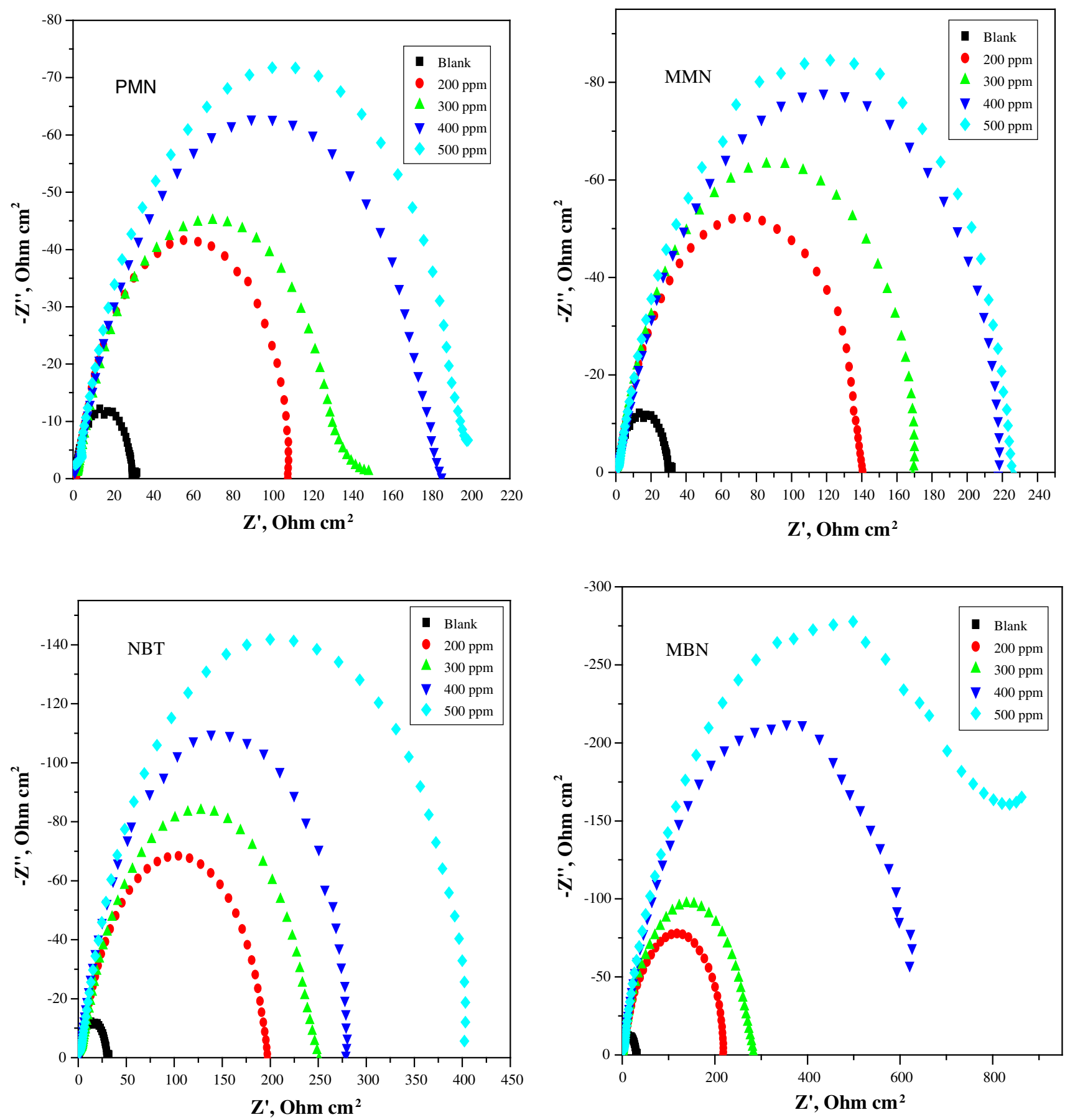

Fig. 12 Nyquist plots for MS in $0.5 \mathrm{M} \mathrm{HCl}$ in the presence of different concentrations of PMN, MMN, NBT and MBN 
Table 5 Impedance parameters for the corrosion of MS in $0.5 \mathrm{M}$ $\mathrm{HCl}$ in the absence and presence of different concentrations of PMN, MMN, NBT and MBN

\begin{tabular}{lclll}
\hline Inhibitor & $C(\mathrm{ppm})$ & $R_{\mathrm{P}}\left(\Omega \mathrm{cm}^{2}\right)$ & $C_{\mathrm{dl}}\left(\mu \mathrm{F} \mathrm{cm}{ }^{-2}\right)$ & IE $(\%)$ \\
\hline Blank & 0 & 27.8 & 322.0 & - \\
PMN & 200 & 95.7 & 91.07 & 71.0 \\
& 300 & 111.8 & 81.01 & 75.1 \\
& 400 & 143.2 & 80.60 & 80.6 \\
& 500 & 163.8 & 64.28 & 83.0 \\
MMN & 200 & 117.8 & 80.66 & 76.4 \\
& 300 & 142.7 & 72.68 & 80.5 \\
& 400 & 172.1 & 65.99 & 83.8 \\
& 500 & 190.5 & 61.96 & 85.4 \\
NBT & 200 & 153.3 & 76.87 & 81.8 \\
& 300 & 191.4 & 66.6 & 85.5 \\
& 400 & 239.7 & 56.88 & 88.4 \\
& 500 & 316.8 & 51.49 & 91.2 \\
MBN & 200 & 172.1 & 65.99 & 83.8 \\
& 300 & 216.3 & 60.41 & 87.1 \\
& 400 & 435.3 & 48.09 & 93.6 \\
& 500 & 562.0 & 36.53 & 95.1 \\
\hline
\end{tabular}

SEM analysis

The SEM images of the polished and corroded MS surface in the absence and presence of inhibitors are shown in Fig. 15a-f. Figure 15a represents the SEM image for polished MS surface. Figure $15 b$ is the SEM image of MS surface in $0.5 \mathrm{M} \mathrm{HCl}$ without inhibitor. It was found that the corroded MS surface contains large number of pits. However, SEM images of MS surface in the presence of

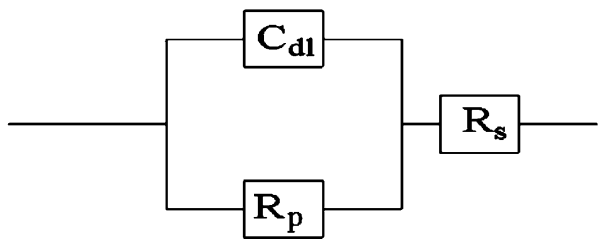

Fig. 13 Equivalent circuit used to fit the impedance spectra

inhibitors (Fig. $15 \mathrm{c}-\mathrm{f}$ ) were observed to be smoother than that of MS surface in $0.5 \mathrm{M} \mathrm{HCl}$ alone. These observations reveal that the inhibitors form protective layer on the MS surface, which prevents the attack of acid as well as the dissolution of MS by forming surface adsorbed layer and thereby reducing the corrosion rate.

\section{Conclusion}

1. All the synthesized nicotinamide derivatives showed good inhibition efficiency for the corrosion of MS in $0.5 \mathrm{M} \mathrm{HCl}$ solutions and the inhibition efficiency found to be time, temperature and concentration dependent.

2. Langmuir adsorption isotherm was found to be the best description for the studied inhibitors, and the negative values of Gibbs free energy of adsorption indicate that the adsorption of inhibitors involves both physisorption and chemisorption process.

3. The inhibition efficiency was found in the order: $\mathrm{MBN}>\mathrm{NBT}>\mathrm{MMN}>\mathrm{PMN}$ and the inhibition efficiencies determined by mass loss, potentiodynamic polarization and EIS methods are in good agreement with each other. 

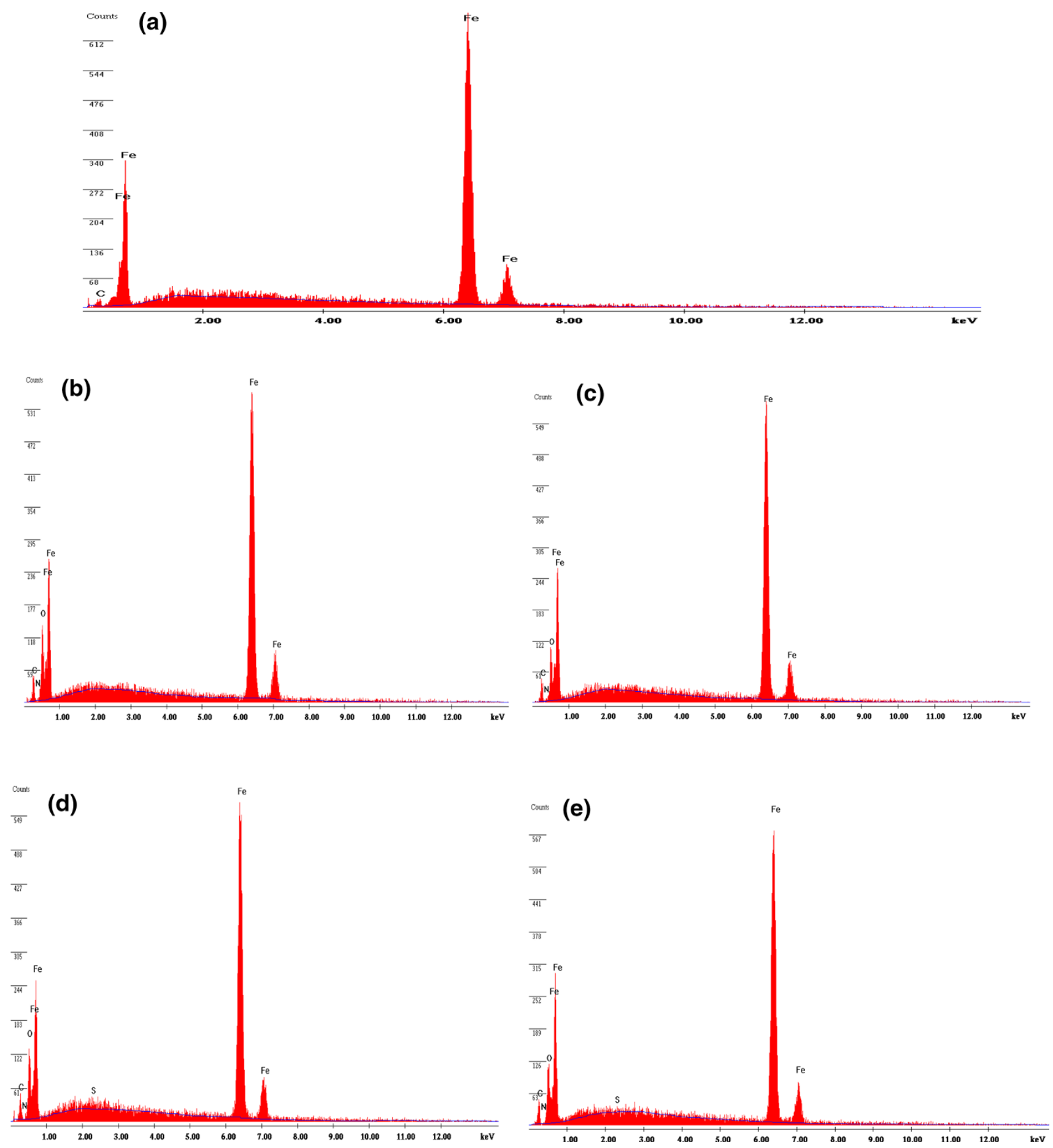

Fig. 14 EDX images of a polished MS surface, b MS in 500 ppm PMN, c MS in 500 ppm MMN, d MS in 500 ppm NBT and e MS in 500 ppm MMN 

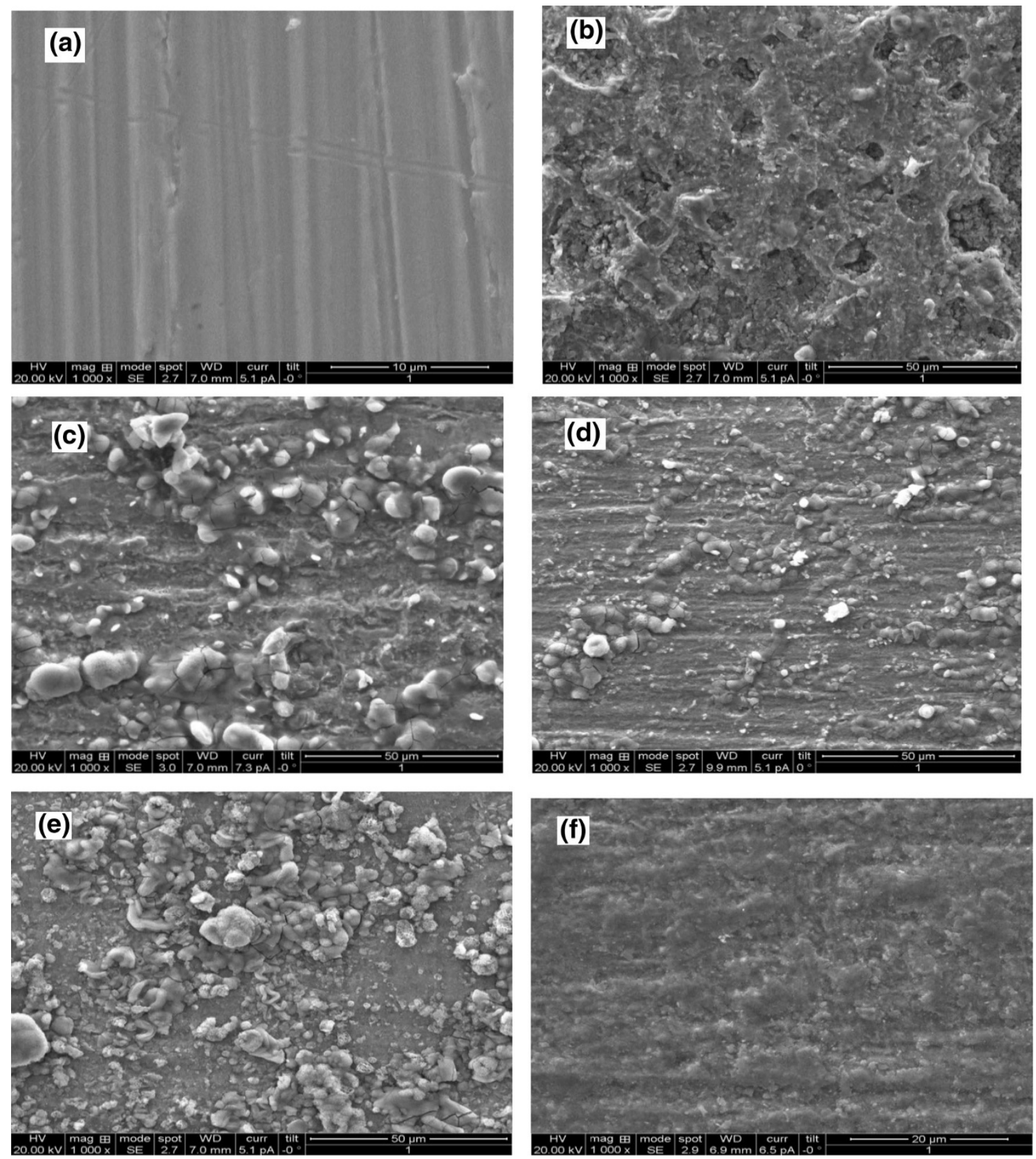

Fig. 15 SEM images of a polished MS surface, b MS in $0.5 \mathrm{M} \mathrm{HCl}$, c MS in 500 ppm PMN, d MS in 500 ppm MMN, e MS in 500 ppm NBT and $\mathbf{f}$ MS in $500 \mathrm{ppm}$ MBN

4. FTIR spectra, scanning electron microscopy (SEM) and energy dispersive X-ray spectroscopy (EDX) were performed to characterize the passive film on the metal surface.

Author's contribution KNM: Writing paper, Guidance. MPC: testing in laboratory. CBP: making set up. All authors read and approved the final manuscript.
Acknowledgments One of the authors (MPC) is grateful to University of Mysore, Mysore for awarding SRF to carry out the research work.

Conflict of interest The authors declare that they have no competing interests.

Open Access This article is distributed under the terms of the Creative Commons Attribution License which permits any use, distribution, and reproduction in any medium, provided the original author(s) and the source are credited. 


\section{References}

1. Nathan NN (1997) Corrosion inhibitors. National association of corrosion engineerings, Houston

2. Trabanelli G (1991) Inhibitors. An old remedy for new challenge. Corros 47:410-419

3. Arena MA, Conde A, De Damborenea J (2002) Cerium: a suitable green corrosion inhibitor for tinplate. Corros Sci 44:511-520

4. Cano E, Pinila P, Pole JL, Bastidas JM (2003) Copper corrosion inhibition by fast green, fuchsin acid and basic compounds in citric acid solution. Mater Corros 54:222-228

5. Dong-Jin C, Youg-Wook K, Jung-Gu K (2001) Development of a blended corrosion, scale, and microorganism inhibitor for open recirculating cooling systems. Mater Corros 52:697-704

6. Moretti G, Guidi F, Grion G (2004) Tryptamine as a green iron corrosion inhibitor in $0.5 \mathrm{M}$ deaerated sulphuric acid. Corros Sci 46:387-403

7. Abd El-Maksoud SA (2008) The effect of organic compounds on the electrochemical behaviour of steel in acidic media. A review. Int J Electrochem Sci 3:528-555

8. Quraishi MA, Sardar R (2003) Corrosion inhibition of mild steel in acid solutions by some aromatic oxadiazoles. Mater Chem Phys 78:425-431

9. Sachin MS, Bilgic S, Yilmaz H (2002) The inhibition effects of some cyclic nitrogen compounds on the corrosion of the steel in $\mathrm{NaCl}$ mediums. Appl Surf Sci 195:1-7

10. Abdulla M, Al-Agez M, Fouda AS (2009) Phenylhydrazone derivatives as corrosion inhibitors for- $\alpha$-brass in hydrochloric acid solutions. Int J Electrochem Sci 4:336-352

11. Bouklah M, Aouniti A, Hammouti B, Benkaddour M, Lagrenee M, Bentiss F (2004) Effect of the substitution of an oxygen atom by sulphur in a pyridazinic molecule towards inhibition of corrosion of steel in $0.5 \mathrm{M} \mathrm{H}_{2} \mathrm{SO}_{4}$ medium. Prog Org Coatings $51: 118-124$

12. Bentiss $F$, Traisnel $M$, Vezin $H$, Hildebrand HF, Lagrenee $M$ (2004) 2,5-Bis(4-dimethylaminophenyl)-1,3,4-oxadiazole and 2,5-bis(4-dimethylaminophenyl)-1,3,4-thiadiazole as corrosion inhibitors for mild steel in acidic media. Corros Sci 46:2781-2792

13. Wang H, Liu R, Xin J (2004) Inhibiting effects of some mercapto-triazole derivatives on the corrosion of mild steel in $1.0 \mathrm{M}$ $\mathrm{HCl}$ medium. Corros Sci 46:2455-2466

14. Karakus M, Sahin M, Bilgic S (2005) An investigation on the inhibition effects of some new dithiophosphonic acid monoesthers on the corrosion of the steel in $1 \mathrm{M} \mathrm{HCl}$ medium. Mater Chem Phys 92:565-571

15. Afidah A, Rahim E, Rocca J, Steinmetz MJ, Kassim RA, Sani Ibrahim M (2007) Mangrove tannins and their flavanoid monomers as alternative steel corrosion inhibitors in acidic medium. Corros Sci 49:402-417

16. Li W, He Q, Pei C, Hou B (2007) Experimental and theoretical investigation of the adsorption behaviour of new triazole derivatives as inhibitors for mild steel corrosion in acid media. Electrochim Acta 52:6386-6394

17. Wang L (2006) Inhibition of mild steel corrosion in phosphoric acid solution by triazole derivatives. Corros Sci 48:608-616

18. Nataraja SE, Venkatesha TV, Manjunath K, Poojary Boja, Pavithra MK, Tandon HC (2011) Inhibition of the corrosion of steel in hydrochloric acid solution by some organic molecules containing the methylthiophenyl moiety. Corros Sci 53:2651-2659

19. Negm NA, Ghuiba FM, Tawfik SM (2011) Novel isoxazolium cationic Schiff base compounds as corrosion inhibitors for carbon steel in hydrochloric acid. Corros Sci 53:3566-3575
20. Ebenso EE, Obot IB, Murulana LC (2010) Quinoline and its derivatives as effective corrosion inhibitors for mild steel in acidic medium. Int J Electrochem Sci 5:1574-1586

21. Ebenso EE, Arslan T, Kandemirli F, Love I, Ogretir C, Saracoglu M, Umoren SA (2010) Theoretical studies of some sulphonamides as corrosion inhibitors for mild steel in acidic medium. Int J Quan Chem 110:2614-2636

22. Loto RT, Loto CA, Popoola API (2012) Corrosion inhibition of thiourea and thiadiazole derivatives: a review. J Mater Environ Sci 3:885-894

23. Bereket G, Hur E, Ogretir C (2002) Quantum chemical studies on some imidazole derivatives as corrosion inhibitors for iron in acidic medium. J Mol Stru (Theochem) 578:79-88

24. Acharya S, Upadhyay SN (2004) The inhibition of corrosion of mild steel by some fluoroquinolones in sodium chloride solution. Trans Indian Inst Met 57:297-306

25. Herrag L, Chetouani A, Elkadiri S, Hammouti B, Aouniti A (2008) Pyrazole derivatives as corrosion inhibitors for steel in hydrochloric acid. Portugal Electrochim Acta 26:211-220

26. Zerga B, Hammouti B, Ebn Touhami M, Touir R, Taleb M, Sfaira M, Bennajeh M, Forssal I (2012) Comparative inhibition study of new synthesized pyridazine derivatives towards mild steel corrosion in hydrochloric acid. Part-II: Thermodynamic proprieties. Int J Electrochem Sci 7:471-483

27. Elewady GY (2008) Pyrimidine derivatives as corrosion inhibitors for carbon steel in $2 \mathrm{M}$ hydrochloric acid solution. Int $\mathrm{J}$ Electrochem Sci 3:1149-1161

28. Praveen Kumar P, Rani BL (2011) Synthesis and characterization of new Schiff bases containing pyridine moiety and their derivatives as antioxidant agents. Int J Chem Tech Res 3:155-160

29. Bentiss F, Lagrenee M, Traisnel M, Hornez JC (1999) The corrosion inhibition of mild steel in acidic media by a new triazole derivative. Corros Sci 41:789-803

30. Singh A, Singh AK, Quraishi MA (2010) Dapsone: a novel corrosion inhibitor for mild steel in acid media. Open Electrochem J 2:43-51

31. Quraishi MA, Hariom K (2002) Sharma, 4-Amino-3-butyl-5mercapto-1,2,4-triazole: a new corrosion inhibitor for mild steel in sulphuric acid. Mater Chem Phys 78:18-21

32. Poornima T, Nayak J, Shetty AN (2012) Corrosion inhibition of the annealed $18 \mathrm{Ni} 250$ grade maraging steel in $0.67 \mathrm{M}$ phosphoric acid by 3,4- dimethoxybenzaldehydethiosemicarbazone. Chem Sci J 69:1-13

33. Abdallah M, Heal EA, Fouda AS (2006) Aminopyrimidine derivatives as inhibitors for corrosion of 1018 carbon steel in nitric acid solution. Corros Sci 48:1639-1654

34. Abd El Rehim SS, Rafaey SAM, Taha F, Saleh MB, Ahmed RA (2001) Corrosion inhibition of mild steel in acidic medium using 2-amino thiophenol and 2-cyanomethyl benzothiazole. J Appl Electrochem 31:429-435

35. Yurt A, Balaban A, Kandemir SU, Bereket G, Erk B (2004) Investigation on some Schiff bases as $\mathrm{HCl}$ corrosion inhibitors for carbon steel. Mater Chem Phys 85:420-426

36. Tang L, Li X, Si Y, Mu G, Liu G (2006) The synergistic inhibition between 8- hydroxyquinoline and chloride ion for the corrosion of cold rolled steel in $0.5 \mathrm{M}$ sulfuric acid. Mater Chem Phys 95:29-38

37. Bhattacharya AK, Naiya TK, Mandal SN, Das SK (2008) Adsorption, kinetics and equilibrium studies on removal of $\mathrm{Cr}(\mathrm{VI})$ from aqueous solutions using different low-cost adsorbents. Chem Engg J 137:529-541

38. Refaey SAM, Taha F, Abd El-Malak AM (2006) Corrosion and inhibition of $316 \mathrm{~L}$ stainless steel in neutral medium by $2-$ mercaptobenzimidazole. Int J Electrochem Sci 1:80-91 
39. Li X, Deng S, Fu H (2011) Three pyrazine derivatives as corrosion inhibitors for steel in $1.0 \mathrm{M} \mathrm{H}_{2} \mathrm{SO}_{4}$ solution. Corros Sci 53:3241-3247

40. Bouklah M, Hammouti B, Lagrenee M, Bentiss F (2006) New thio-compounds as corrosion inhibitor for steel in $1 \mathrm{M} \mathrm{HCl}$. Corros Sci 48:2470-2479

41. Bayoumi FM, Ghanem WA (2005) Corrosion inhibition of mild steel using naphthalene disulfonic acid. Mater Letts 59: 3806-3809

42. Yurt A, Balaban A, Ustun Kandemir S, Bereket G, Erk B (2004) Investigation on some Schiff bases as $\mathrm{HCl}$ corrosion inhibitors for carbon steel. Mater Chem Phys 85:420-426

43. Li X, Deng S, Fu H, Li T (2009) Adsorption and inhibition effect of 6-benzylaminopurine on cold rolled steel in $1.0 \mathrm{M} \mathrm{HCl}$. Electrochim Acta 54:4089-4098

44. Lebrini M, Bentiss F, Vezin H, Lagrenee M (2005) Inhibiting effects of some oxadiazole derivatives on the corrosion of mild steel in perchloric acid solution. Appl Surf Sci 252:950-958

45. Musa AY, Kadhum AAH, Mohamad AB, Takriff MS, Daud AR, Kamarudin SK (2010) On the inhibition of mild steel corrosion by 4-amino-5-phenyl-4H-1,2,4-trizole-3-thiol. Corros Sci 52: $526-533$

46. Juttner K (1990) Electrochemical impedance spectroscopy (EIS) of corrosion processes on inhomogeneous surfaces. Electrochim Acta 35:1501-1508

47. Bentiss F, Lebrini M, Langrenee M, Traisnel M, Elfarouk A, Vezin H (2007) The influence of some new 2,5-disubstituted 1,3,4-thiadiazoles on the corrosion behaviour of mild steel in $1 \mathrm{M}$ $\mathrm{HCl}$ solution: AC impedance study and theoretical approach. Electrochim Acta 52:6865-6872
48. El-Taib Heakal F, Ghoneim AA, Fekry AM (2007) Stability of spontaneous passive films on high strength Mo-containing stainless steels in aqueous solutions. J Appl Electrochem 37: 405-413

49. Lebrini M, Bentiss F, Vezin H, Lagrene M (2006) The inhibition of mild steel corrosion in acidic solutions by 2,5-bis(4-pyridyl)1,3,4-thiadiazole: structure-activity correlation. Corros Sci 48:1279-1291

50. Shukla SK, Quaraishi MA (2010) The effects of pharmaceutically active compound doxycycline on the corrosion of mild steel in hydrochloric acid solution. Corros Sci 52:314-321

51. Bentiss F, Traisnel M, Lagrenee M (2000) The substituted 1,3,4oxadiazoles: a new class of corrosion inhibitors of mild steel in acidic media. Corros Sci 42:127-146

52. Parameswari K, Chaitra S, Nusrath Unnisa C, Selvaraj A (2010) Effect of azlactones on corrosion inhibition of mild steel in acid medium. J Appl Sci Res 6:1100-1110

53. Aloui S, Forsal I, Sfaira M, Ebn Touhami M, Taleb M, Filali Baba M, Daoudi M (2009) New mechanism synthesis of 1,4benzothiazine and its inhibition performance on mild steel in hydrochloric acid. Portugaliae Electrochim Acta 27:599-613

54. Zaafarany I (2009) Phenyl phthalimide as corrosion inhibitor for corrosion of C-Steel in sulphuric acid solution. Portugaliae Electrochim Acta 27:631-643

55. Ahamad I, Quraishi MA (2009) Bis (benzimidazol-2-yl) disulphide: an efficient water soluble inhibitor for corrosion of mild steel in acid media. Corros Sci 51:2006-2013 